Discussion Paper 144

Institute for Empirical Macroeconomics

Federal Reserve Bank of Minneapolis

90 Hennepin Avenue

Minneapolis, Minnesota 55480-0291

October 2006

\title{
Ben-Porath Meets Skill-Biased Technical Change: A Theoretical Analysis of Rising Inequality*
}

\author{
Fatih Guvenen and Burhanettin Kuruscu \\ University of Texas at Austin
}

\begin{abstract}
In this paper we present an analytically tractable general equilibrium overlapping-generations model of human capital accumulation, and study its implications for the evolution of the U.S. wage distribution from 1970 to 2000. The key feature of the model, and the only source of heterogeneity, is that individuals differ in their ability to accumulate human capital. Therefore, wage inequality results only from differences in human capital accumulation. We examine the response of this model to skill-biased technical change (SBTC) theoretically. We show that in response to SBTC, the model generates behavior consistent with the U.S. data including (i) a rise in overall wage inequality in both the short run and long run, (ii) an initial fall in the education premium followed by a strong recovery, leading to a higher premium in the long run, (iii) the fact that most of this fall and rise takes place among younger workers, (iv) stagnation in median wage growth (and a slowdown in aggregate labor productivity), and (v) a rise in consumption inequality that is much smaller than the rise in wage inequality. These results suggest that the heterogeneity in the ability to accumulate human capital is an important feature for understanding the effects of SBTC, and interpreting the transformation that the U.S. economy has gone through since the 1970s.
\end{abstract}

\footnotetext{
*guvenen@eco.utexas.edu; www.eco.utexas.edu/faculty/guvenen; kuruscu@eco.utexas.edu; www.eco.utexas.edu/ kuruscu. For helpful comments and suggestions, we thank Satyajit Chatterjee, Dean Corbae, Tom Sargent, Rob Shimer, Kjetil Storesletten, Aleh Tsyvinski, Gustavo Ventura, Gianluca Violante, Amir Yaron, and especially David Autor and Steve Davis, as well as the seminar participants at the European University Institute, Goethe University Frankfurt, HEC Lausanne, Humboldt University, London School of Economics, Philadelphia FED, Rice University, University of Michigan, University of Rochester, University of Toulouse, UT-Austin, University of Zurich, NBER's Economic Fluctuations and Growth Meeting in Cambridge, Minnesota Macro Workshop, the "Labor Supply and Life-Cycle Productivity" Workshop organized by the Bank of Canada, and the SED conference. We are especially grateful to Daron Acemoglu for comments and suggestions that substantially improved the paper. David Autor kindly provided the data on U.S. male wages used in the paper. Guvenen acknowledges financial support from the National Science Foundation (SES-0351001). An earlier longer version of this paper circulated under the title "Understanding Wage Inequality: Ben-Porath Meets Skill-Biased Technical Change.” The views expressed herein are those of the authors and not necessarily those of the Federal Reserve Bank of Minneapolis or the Federal Reserve System.
} 


\section{Introduction}

The Ben-Porath (1967) model of human capital accumulation has been one of the workhorses in labor economics in the last 40 years. It has been extensively used to understand such issues as educational attainment, on-the-job training, and wage growth over the life cycle, among others. It is then perhaps surprising that this model has not been applied to the same extent to study the significant changes observed in the U.S. labor markets since the early 1970s. The goal of this paper is to close this gap. In particular, this paper develops and studies the theoretical implications of a human capital model (which builds on Ben-Porath (1967)) for the evolution of the wage distribution during this period. The particular model studied is an analytically tractable, general equilibrium, overlapping-generations model, where the key novel feature is that individuals differ significantly in their ability to accumulate human capital. This is the only source of heterogeneity in this model, and this assumption is motivated by some recent empirical evidence discussed below.

Specifically, this paper focuses on the following three dimensions of the changes in the wage distribution from about 1970 to $2000:^{1}$

1. The stagnation of median wages (and the slowdown in labor productivity) from about 1973 to 1995 (i.e., changes in the first moment of the wage distribution).

2. The substantial changes in overall, between-group and within-group wage inequality during this period (i.e., changes in the second moment of the wage distribution).

3. The relatively small rise in consumption inequality despite the large rise in wage inequality (i.e., changes in lifetime wage income distribution).

Among the trends mentioned above, perhaps the most puzzling has been the joint behavior of overall wage inequality and between-group inequality (i.e., the education premium), and in particular, their movement in opposite directions during the 1970s. Juhn, Murphy, and Pierce (1993) have documented these patterns and stated: "The rise in within-group inequality preceded the increase in returns to observables by over a decade. On the basis of this difference in timing, it seems clear to us that there are at least two unique dimensions of skill (education and skill differences within an education group) that receive unique prices in the labor market" (p. 429). They then added: "Our conclusion is that the general rise in inequality and the rise in education premium are actually distinct economic phenomena" (p. 412). This widely accepted conclusion has then led most of the subsequent literature to search for separate driving forces and mechanisms to explain each of these phenomena. ${ }^{2}$ Instead, as we elaborate below, this paper proposes a mechanism that simultaneously generates a monotonic rise in overall inequality and a non-monotonic change in the education premium, despite the fact that the model has one type of skill.

\footnotetext{
${ }^{1}$ For extensive documentation of these trends, see Bound and Johnson (1992), Katz and Murphy (1992), Murphy and Welch (1992), Juhn, Murphy, and Pierce (1993), Card and Lemieux (2001), Acemoglu (2002), Krueger and Perri (2006), Attanasio, Battistin, and Ichimura (2004), and Autor, Katz, and Kearney (2005a,b).

${ }^{2}$ Some notable exceptions are discussed in the literature review.
} 
Here are the basic features of the model. Individuals begin life with a fixed endowment of "raw labor" (i.e., strength, health, etc.) and are able to accumulate "human capital" (skills, knowledge, etc.) over the life cycle. Raw labor and human capital earn separate wages in the labor market and each individual supplies both of these factors of production at competitively determined prices (wages). Investment in human capital takes place on-the-job unless it equals 100 percent of an individual's time, in which case it is interpreted as "schooling." Individuals who invest full-time for a specified number of years are defined as college graduates. We assume that skills are general (i.e., not firm-specific) and labor markets are competitive. As a result, the cost of human capital investment will be completely borne by the workers, and firms will adjust the hourly wage rate downward by the fraction of time invested on the job (Becker (1965)). Thus, the cost of human capital investment is the foregone earnings while individuals are learning new skills. The model described so far is essentially the same as the standard Ben-Porath framework, except for the fact that we distinguish between raw labor and human capital, for reasons that will become clear below.

We introduce two features into this framework. First, we assume that individuals differ in their ability to accumulate human capital. As a result, individuals differ systematically in the amount of investment they undertake, and consequently, in the growth rate of their wages over the life cycle. This assumption is consistent with the recent empirical evidence from panel data on individual wages; see, for example, Lillard and Weiss (1979), Baker (1997), Guvenen (2005a,b), and Huggett, Ventura, and Yaron (2005). Thus, wage inequality in the model results entirely from the systematic fanning out of wage profiles over the life cycle.

The demand side of the model consists of a linear production technology that takes raw labor and human capital as inputs. The second element in the model, and the driving force behind the non-stationary changes during this period, is skill-biased technical change (SBTC) that occurs starting in the early 1970s (for empirical evidence on SBTC, see, for example, Berman, Bound, and Griliches (1994), Autor, Katz, and Krueger (1998), and Machin and Van Reenen (1998)). A key difference of our model is that we do not equate "skill" to education as has often been done in previous studies. Instead, we interpret skill more broadly as human capital and view SBTC as a change that raises the productivity of human capital relative to raw labor. ${ }^{3}$ This seemingly small difference in perspective has important consequences. To see this, note that in this model all workers have some amount of human capital (which varies by ability and age) and raw labor (which is the same for all). Therefore, SBTC does not only change wages between education groups (because of differences in average human capital levels), but it also affects wages within each group differently, depending on the ability and age of each individual. In this framework education is not a separate skill with its unique price, but is merely a noisy indicator of an individual's ability to learn, which in turn is an indicator of his human capital level and of how strongly he responds to

\footnotetext{
${ }^{3}$ If there were only one factor of production (say, human capital), an increase in its productivity would entail a parallel increase in aggregate productivity (TFP), which is not consistent with empirical evidence during this period. Instead, the existence of two factors in this framework allows us to model SBTC as a change in the productivity of human capital relative to raw labor, without necessarily implying anything about TFP growth.
} 
SBTC. Therefore, another feature of this model is that it allows us to study both between-group and within-group inequality simultaneously.

The linear production function allows us to solve the model in closed form, derive explicit expressions for the moments of the wage and consumption distributions, and establish our results theoretically. In addition to this analytical convenience, however, the linear form (i.e., perfect substitutability) plays another important role. With imperfect substitution, the college premium would be negatively related to the relative supply of college graduates. Several authors have emphasized this link to argue that the fall in the college premium during the 1970s resulted from the rapid increase in the supply of college-educated workers (cf., Katz and Murphy (1992), Juhn, Murphy, and Pierce (1993)). When the production function is linear, however, this link is broken. Therefore, we use this linear technology to highlight a different mechanism, and to show that our results - and especially the non-monotonic behavior of the college premium - are not driven by the relative supply channel emphasized in earlier work. Of course, in reality both channels are probably operational and are complementary to each other.

We first examine the behavior of average wages in response to SBTC. Under a fairly mild assumption, the model generates stagnation in average wages in the short run after SBTC and a rise in the long run. The mechanism can be explained as follows. Because SBTC raises the returns to human capital at all future dates, it leads to a permanent increase in investment rates, since individuals are forward-looking. While this higher investment results in an immediate increase in costs (in the form of foregone earnings), its benefits are realized gradually as the total stock of human capital slowly increases. As a result, observed wages fall in the short run, due to increased investment on the job, and inherit the sluggish growth of the human capital stock thereafter.

Second, a closely related mechanism generates the non-monotonic behavior of the college premium during SBTC. Basically, because college graduates have higher learning ability than those with lower education, their investment increases more in response to SBTC. This differential increase in immediate costs (i.e., foregone earnings) results in a fall in their relative wages in the short run. In the long run, however, this higher investment yields a larger increase in their human capital stock, leading to a higher college premium. It is also easy to see that this mechanism will affect younger workers - who have a longer horizon and thus expect larger benefits from investing - more than older ones, resulting in a more pronounced decline in the college premium among younger workers, consistent with empirical evidence (Katz and Murphy (1992), Card and Lemieux (2001)). In addition, despite the fall in the college premium in the short run, it can be shown that overall wage inequality rises in the model during the same time (proposition 4). Therefore, taken together the last two results show that this model is consistent with the joint behavior of overall wage inequality and between-group inequality observed in the U.S. data mentioned above. ${ }^{4}$

\footnotetext{
${ }^{4}$ Furthermore, the model is also consistent with an important recent finding by Autor, Katz, and Kearney (2005b), who document that most of the increase in overall wage inequality happened at the upper tail of the distribution. (In particular, they report that 90 percent of the increase in male 90-10 percentile wage inequality between 1979 and
} 
Figure 1: The Effect of the Returns to Human Capital on Life-Cycle Wage Profiles
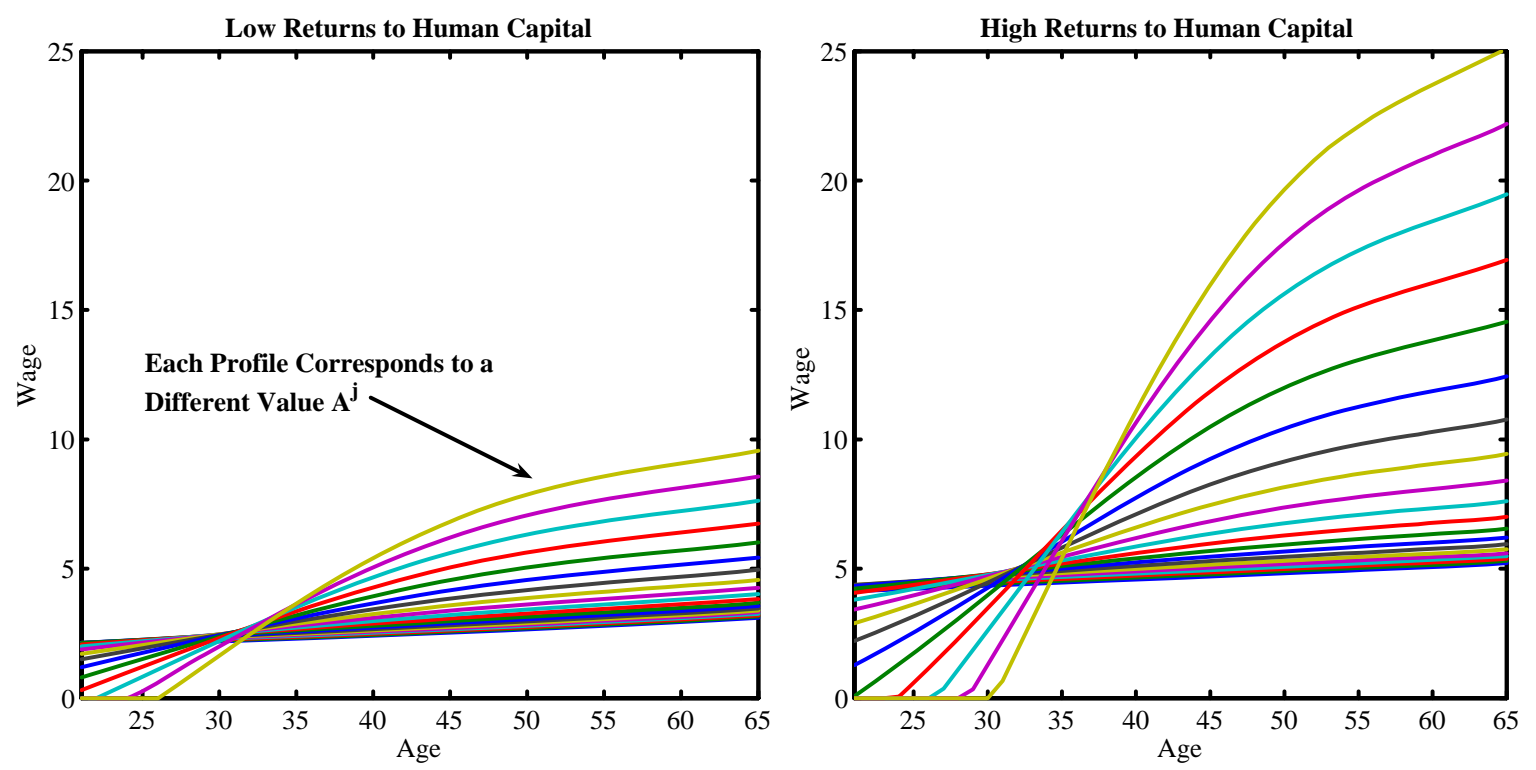

Third, and finally, the rise in lifetime income inequality in the model is significantly smaller than the rise in wage inequality. The main reason for this result can be seen in figure 1. A high price of human capital (right panel) generates larger cross-sectional wage inequality because of a fanning out of wage profiles. However, note that those individuals who experience a large increase in their wages later in life are exactly those who make larger investments and accept lower wages early on. Because future gains are discounted compared to the early losses in calculating lifetime income, the rise in lifetime inequality remains small. Therefore, the model offers a new mechanism that rationalizes a small change in lifetime inequality with the large increase in wage inequality.

In Section 4 we briefly examine some quantitative implications of the model. We calibrate the model to the U.S. data before 1970, and then analyze the behavior of some of the variables during SBTC - which is assumed to start in 1970 and continue until 1995. Despite the stylized nature of the model, it provides a fairly good quantitative explanation for the broad trends during this period. In a companion paper (Guvenen and Kuruscu (2006)), we relax several assumptions made in the current paper for analytical tractability, and introduce some important missing features - such as replacing the perfect foresight assumption about future skill prices with Bayesian learning, allowing for imperfect substitution in the production function, and introducing uncertainty, among others. The detailed quantitative analysis in that paper shows that the main mechanisms highlighted in

2003 is accounted for by the rise in 90-50 percentile wage gap.) As we show in Section 3, in this model the investment response to SBTC increases - in fact, non-linearly — with ability, resulting in wage inequality rising significantly more above the median compared to below the median. In fact this feature is apparent in figure 1, which plots the average wage profiles for twenty-quantiles of the wage distribution before and after SBTC. 
this paper continue to play a central role, and the main conclusions of this paper carry over to that more general case.

There is a vast literature on the empirical trends that motivate this paper. A short list of these papers is mentioned in footnote 1; for excellent surveys of the literature see Katz and Autor (1999) and Acemoglu (2002). An important precursor to our paper is Heckman, Lochner, and Taber (1998), who quantitatively examine the implications of an overlapping-generations model of human capital accumulation for some of the trends mentioned above. This paper differs from theirs in several respects. First, the model studied here is simpler than theirs in several dimensions, which allows us to solve the model analytically and establish our results theoretically. Second, a central thesis of our paper is that individuals differ significantly in their ability to accumulate human capital, which is not the case in their paper. Third, the present is a one-skill model, whereas theirs has two skills.

Several studies before us have emphasized the role of a rapid increase in the demand for skill for rising wage inequality. Important examples include Greenwood and Yorukoglu (1997), Galor and Tsiddon (1998), Caselli (1999), Aghion, Howitt, and Violante (2002), and Violante (2002). Greenwood and Yorukoglu (1997) emphasize the role of skill in facilitating the adoption of new technologies. They argue that the advent of computer technologies in the 1970s presented such a change, which increased the wages of skilled workers and resulted in a productivity slowdown due to the time it takes to utilize the new technologies effectively. Caselli (1999) studies a model where differences in innate ability and newer technologies that are more costly to learn than existing ones result in a higher wage inequality (rising skill premium). Violante (2002) develops a model of within-group inequality, in which vintage-specific skills, embodied technological acceleration, and labor market frictions combine to generate a rise in inequality. In all three of these papers, technological change is "embodied" in new machines, whereas in our paper it is "disembodied." It is possible to argue that both types of technological changes have been taking place during this period, so the mechanisms emphasized in these papers are complementary to ours.

Several papers have proposed explanations for the (non-monotonic) behavior of the college premium during this period. In an influential paper, Katz and Murphy (1992) show that a simple supply-demand framework provides a very good fit to the observed behavior of the college premium. Acemoglu (1998) goes one step further and proposes a model to endogenize the demand for skill: essentially, a large rise in the supply of college workers causes firms to direct their innovations to take advantage of this supply, creating an endogenous skill-bias in technological progress. He also shows that an extension of this model with two skills is potentially consistent with the joint behavior of college premium and total wage inequality. Similarly, Krusell et al. (2000) show that an increased demand for skills can result if capital and skills are complementary in the production function, and technical change is investment-specific. Galor and Moav (2000) discuss an extension of their baseline model that can also explain the joint behavior of college premium and total wage 
inequality (although they do not fully develop the model). ${ }^{5}$ As noted above, a feature common to these papers is the central role played by the relative supply of skill, which arises from a production function with imperfect substitution between workers with different skill levels. Instead, here we eliminate the effect of relative supply on skill prices, and emphasize a different channel that works through the change in the quantity of human capital in response to SBTC. In fact, the differential investment response is the key for the initial decline of the college premium in our framework. In addition, the joint behavior of between-group and overall inequality in this model results from a single driving force.

The paper is organized as follows. The next section describes the model. Section 3 presents the theoretical analysis and establishes the results described above. Section 4 presents some quantitative evidence, and Section 5 concludes.

\section{A Baseline Model}

\subsection{Human Capital Accumulation Decision}

The economy consists of overlapping generations of individuals who live for $S$ years. Individuals begin life with an endowment of "raw labor" (i.e., strength, health, etc.), which is the same across individuals and constant over the life cycle, and are able to accumulate "human capital" (skills, knowledge, etc.) over the life cycle, which is the only skill that can be accumulated in this economy. There is a continuum of individuals in every cohort, indexed by $j \in[0,1]$, who differ in their ability to accumulate human capital, denoted by $\widetilde{A}_{j}$ (also referred to as their "type"). This is the only source of heterogeneity in the model.

Each individual has one unit of time endowment in each period that can be allocated between producing output and accumulating human capital. Let $l$ denote raw labor and $h_{j, s}$ denote the human capital of an $s$-year-old individual of type $j$. We assume that raw labor and human capital earn separate wages in the labor market, and each individual supplies both of these factors of production at competitively determined wage rates. Therefore, the "potential income" of an individual - that is, the income he would earn if he spent all his time producing for his employeris given by $P_{L} l+P_{H} h_{j, s}$, where $P_{L}$ and $P_{H}$ are the rental prices of raw labor and human capital, respectively. (For clarity of notation, we suppress the dependence of variables on time, except when we specifically want to emphasize time variation.)

Following the standard interpretation of the Ben-Porath (1967) model, we assume that investment in human capital takes place on-the-job unless it equals 100 percent of an individual's time, in which case it is interpreted as "schooling." We assume that skills are general (i.e., not firm-specific)

\footnotetext{
${ }^{5}$ Gould, Moav, and Weinberg (2001) develop a model that can also generate the different behaviors of betweenand within-group inequality during this period. However, their explanation relies on the existence of two separate sources of inequality growth.
} 
and labor markets are competitive. As a result, the cost of human capital investment will be completely borne by workers, and firms will adjust the hourly wage rate downward by the fraction of time invested on the job (Becker (1965)). Then, the observed wage income of an individual is given by

$$
w_{j, s}=\left[P_{L} l+P_{H} h_{j, s}\right]\left(1-i_{j, s}\right)=\underbrace{\left[P_{L} l+P_{H} h_{j, s}\right]}_{\text {Potential earnings }}-\underbrace{\left[P_{L} l+P_{H} h_{j, s}\right] \times i_{j, s}}_{\text {Cost of investment }},
$$

where $i_{j, s}$ is the fraction of time spent on human capital investment, henceforth referred to as "investment time." Thus, wage income can be written as the potential earnings minus the "cost of investment," which is simply the foregone earnings while individuals are learning new skills. Since labor supply is inelastic (i.e., conditional on working, all workers supply one unit of time per period), $w_{j, s}$ is also the observed (hourly) wage rate.

Individuals begin their life with zero human capital, $h_{j, 0}=0$, and accumulate human capital according to the following technology:

$$
h_{j, s+1}=h_{j, s}+Q_{j, s}
$$

where $Q_{j, s}$ is the newly produced human capital, which will be referred to simply as "investment" in the rest of the paper, and should not be confused with investment time $\left(i_{j, s}\right)$. New human capital is produced by combining the existing stocks of raw labor and human capital with the available investment time according to

$$
Q_{j, s}=\widetilde{A}_{j}\left(\left(\theta_{L} l+\theta_{H} h_{j, s}\right) i_{j, s}\right)^{\alpha}
$$

The key parameter in this specification is $\widetilde{A}_{j}$, which determines the productivity of learning. Due to the heterogeneity in $\widetilde{A}_{j}$, individuals will differ systematically in the amount of investment they undertake, and consequently, in the growth rate of their wages over the life cycle. Another important parameter is $\alpha \in[0,1]$, which determines the degree of diminishing marginal returns in the human capital production function. A low value of $\alpha$ implies higher diminishing returns, in which case it is optimal to spread out investment over time. In contrast, when $\alpha$ is high, the marginal return on investment does not fall quickly, and investment becomes bunched over time. In the extreme case when $\alpha=1$, individuals will spend either all their time on investment $\left(i_{j, s}=1\right)$ or none at all in a given period. Finally, the parameters $\theta_{L}$ and $\theta_{H}$ determine the relative contributions of each factor to human capital accumulation, and could be time-varying as well.

The main difference between the Ben-Porath (1967) model and the formulation in (3) is the introduction of raw labor as an additional factor into our model. When $l \equiv 0$ (and $\theta_{H}$ is normalized to 1), this model reduces to the standard Ben-Porath model. As will be clear in the analysis below, the reason for our deviation from the standard Ben-Porath model is because it is difficult to sensibly think about SBTC when there is a single factor of production. 


\subsection{Individual's Dynamic Problem}

We assume that individuals can borrow and lend at a constant interest rate (denoted by $r$ ), which implies that markets are complete. As is well-known, in this case the consumption-savings and income maximization decisions can be disentangled from each other. Therefore, for the purposes of analyzing human capital investment, we concentrate on the lifetime income maximization problem. Individuals solve

$$
\max _{\left\{i_{j, s}\right\}_{s=1}^{S}}\left[\sum_{s=1}^{S}\left(\frac{1}{1+r}\right)^{s-1}\left[P_{L} l+P_{H} h_{j, s}\right]\left(1-i_{j, s}\right)\right]
$$

subject to $(2),(3)$, and $h_{j, 0}=0$. It should be stressed that this formulation does not rest on the assumption of risk-neutrality, but only requires markets to be complete.

\subsection{Aggregate Production Technology}

The aggregate factors used in production at a point in time are defined as

$$
\begin{aligned}
L^{n e t} & =\sum_{s=1}^{S} \mu(s) \int_{j} l\left(1-i_{j, s}\right) d j, \text { and } \\
H^{n e t} & =\sum_{s=1}^{S} \mu(s) \int_{j} h_{j, s}\left(1-i_{j, s}\right) d j,
\end{aligned}
$$

where $\mu(s)$ is the (discrete) measure of $s$-year-old individuals, and the sums are thus taken over the distribution of individuals of all types and ages. ${ }^{6}$ The superscript "net" indicates that these variables measure the actual amounts of each factor used in production (that is, net of the time allocated to human capital investment) to distinguish them from the "total stocks" of these factors available in the economy, which are defined later below. The aggregate firm uses these two inputs to produce a single good, denoted by $Y$ according to

$$
Y=Z\left(\theta_{L} L^{n e t}+\theta_{H} H^{n e t}\right)
$$

where $Z$ is the total factor productivity (TFP). For simplicity we assume that capital is not used in production. Note that raw labor and human capital enter the aggregate production function and human capital production in a symmetric manner and with the same productivity parameters (compare (4) to (3)). ${ }^{7}$ This assumption allows us to solve the model in closed form.

\footnotetext{
${ }^{6}$ For the population structure assumed so far, $\mu(s)=1 / S$.

${ }^{7}$ In the calibrated version of this model (Guvenen and Kuruscu (2006)), we have experimented with three other specifications of the human capital accumulation function that also seemed a priori plausible. In particular, we write the human capital function as $\widetilde{A}_{j}\left(\left(\lambda_{L, t} l+\lambda_{H, t} h_{j, s}\right) i_{j, s}\right)^{\alpha}$ and consider (i) weights that remain constant through SBTC: $\lambda_{L, t}=\bar{\lambda}_{L}$ and $\lambda_{H, t}=\bar{\lambda}_{H}$; (ii) an aggregate production function that features imperfect substitution between
} 
The firm solves a static problem by hiring factors from households every period to maximize its profit: $Y-P_{L} L^{n e t}-P_{H} H^{n e t}$. As a result, the factor prices are given by the marginal products

$$
P_{H}=\partial Y / \partial H^{n e t}=\theta_{H} \quad \text { and } \quad P_{L}=\partial Y / \partial L^{n e t}=\theta_{L} .
$$

It is useful to compare this production structure to that assumed in some of the previous literature. In these papers, the production technology is typically taken to be a CES function: $Z\left[\left(\theta_{L} L\right)^{\rho}+\left(\theta_{H} H\right)^{\rho}\right]^{1 / \rho}$, where now $H$ and $L$ denote the total work hours of college and highschool workers, respectively. Therefore, in these models, a change in $\theta_{H} / \theta_{L}$ due to SBTC has the same effect on all individuals within a given education group. Instead, here we interpret skill more broadly as human capital and do not equate it to education. Since all workers in this model have some amount of human capital (which varies by ability and age) and raw labor (which is the same for all), SBTC not only changes wages between education groups (because of differences in average human capital levels), but also affects wages within each group differently, depending on the ability and age of each individual. In this sense, this model allows us to study both between-group and within-group inequality simultaneously.

A second implication of the production function assumed in these studies is that the education premium is given by $P_{H} / P_{L}=\left(\theta_{H} / \theta_{L}\right)^{\rho}(H / L)^{\rho-1}$ and is therefore decreasing in the relative supply of college graduates. Several authors have emphasized this link to argue that the fall in the college premium during the 1970s resulted from the rapid increase in the supply of college-educated workers (cf., Katz and Murphy (1992), Juhn, Murphy, and Pierce (1993)). However, notice that when the production function is linear, this link is broken: $P_{H} / P_{L}=\theta_{H} / \theta_{L}$. Thus, we use this linear production technology to show that the non-monotonic behavior of the college premium in this paper is not driven by the relative supply channel emphasized in earlier work.

\subsection{Analyzing the Individual's Problem}

We next rewrite the problem to simplify the exposition. Using equation (3), the opportunity cost of investing an amount $Q_{j, s}$ can be written as

$$
C_{j}\left(Q_{j, s}\right) \equiv\left(\theta_{L} l+\theta_{H} h_{j, s}\right) i_{j, s}=\left(\frac{Q_{j, s}}{\widetilde{A}_{j}}\right)^{1 / \alpha} .
$$

raw labor and human capital, and weights that are proportional to wages: $\lambda_{L, t}=P_{L, t}$ and $\lambda_{H, t}=P_{H, t}$; and (iii) no role for raw labor in human capital production: $\lambda_{L, t}=0$ and $\lambda_{H, t}=1$. The first two cases had implications qualitatively similar to the baseline model described here, while the third displayed some implausible behavior even in steady state (that is, without SBTC). Overall, and perhaps surprisingly, the simplest specification we adopt here for analytical convenience (given in equation (3)) also turned out to have the most plausible quantitative implications. 
With this transformation, the problem of an individual can be written as

$$
\max _{\left\{Q_{j, s}\right\}_{s=1}^{S}}\left[\sum_{s=1}^{S}\left(\frac{1}{1+r}\right)^{s-1}\left(\theta_{L} l+\theta_{H} h_{j, s}-C_{j}\left(Q_{j, s}\right)\right)\right]
$$

subject to

$$
h_{j, s+1}=h_{j, s}+Q_{j, s}, \quad \text { with } h_{j, 0}=0 .
$$

The optimality condition which determines the amount of investment at time $t$ is

$$
C_{j}^{\prime}\left(Q_{j, s}\right)=\frac{1}{1+r}\left\{\theta_{H}(t+1)+\frac{\theta_{H}(t+2)}{1+r}+\ldots+\frac{\theta_{H}(t+S-s-1)}{(1+r)^{S-s-1}}\right\}
$$

where we make explicit the dependence of future prices of human capital on time. The left-hand side of this equation is the marginal cost, and the right-hand side is the marginal benefit $(M B)$ of investment. The latter is the present discounted value of the future stream of wages that is earned by an additional unit of human capital. An important implication of (5) is that an expected increase in the future prices of skill (the sequence $\theta_{H}(t)$ ) will have an immediate impact on current investment decisions because of the forward-looking nature of this equation.

Remark. - The optimality condition (5) highlights an important difference between the current framework and the Ben-Porath model. In the latter, the optimality condition is given by

$$
W(t) C_{j}^{\prime}\left(Q_{j, s}\right)=\frac{1}{1+r}\left\{W(t+1)+\frac{W(t+2)}{1+r}+\ldots+\frac{W(t+S-s-1)}{(1+r)^{S-s-1}}\right\},
$$

where $W(t)$ is the wage rate in period $t$, which in turn equals the price of human capital since it is the only factor of production in that model. Now, suppose that the economy is in steady state with $W(t)=\bar{W}$ for all $t$, and consider the effect of a one-time permanent increase in the wage rate. This change will only have an effect on investment in the first period, but not after that. This is because a permanently higher $W$ will increase both the cost and the benefit of investment by the same amount, after the first period. Although it is possible to generate a persistent increase in investment rates by increasing the growth rate of $W$, there is no evidence of increased TFP growth after the 1970s; in fact there is ample evidence to the contrary. In contrast, in the present framework SBTC takes the form of a permanent increase in $\theta_{H}$ relative to $\theta_{L}$. This increases the benefit of human capital investment (right-hand side of (5)) relative to the cost of investment (lefthand side), and therefore increases the incentives to invest in human capital permanently, without necessarily implying anything about TFP growth.

We now return to analyzing the individual's problem. To illustrate how the model works, consider two economies that differ only in the price of human capital, $\theta_{H}$ and $\theta_{H}^{\prime}$ with $\theta_{H}^{\prime}>\theta_{H}$. Figure 1 compares the wage profiles of individuals with different ability levels in these two cases. First, note the features common to both cases: workers with high ability invest more than others, 
accepting lower wages early on in return for higher wages later in life. As a result, wage inequality increases over the life cycle due to the systematic fanning out of the wage profiles. Workers with ability level above a certain threshold invest full time early in life (they attend college).

A comparison of these two economies reveals a number of important points that are key to understanding the results of this paper about the long-run effects of SBTC. First, a higher price of human capital induces more investment, where the strength of this response increases with ability. As a result, cross-sectional wage inequality increases due to the fanning out of wage profiles. Notice, however, that lifetime income inequality will not rise as much as cross-sectional wage inequality because those with high wages later on are exactly those who invest more, and therefore have low wages early in the life cycle. Moreover, since lifetime income is a discounted average of wages over the life cycle, later gains are discounted compared to early losses, so the rise in the lifetime income of high ability individuals remains modest.

\section{Theoretical Analysis}

In this section we consider a simplified demographic structure that allows us to establish our main results theoretically. In particular we specialize to the "perpetual youth" version of the overlappinggenerations model as in Blanchard (1985): individuals can potentially live forever $(S=\infty)$ but face a constant probability of death $(1-\delta)$ every period. Under this assumption, $s$ is no longer a state variable in the human capital problem, simplifying the analysis substantially. We normalize the population size to one, and assume that each period a cohort of measure $(1-\delta)$ is born to replace the individuals who die. Therefore, the measure of an $s$-year-old cohort is given by $\mu(s)=(1-\delta) \delta^{s-1}$. In the rest of the analysis, we restrict our attention to an interior solution; hence we assume that $w_{j, s} \geq 0$ for all $j, s$. This provides analytical tractability. ${ }^{8}$ Finally, we assume that $r=1 /(\delta \beta)-1$, which implies that individuals choose a constant consumption path over the life cycle.

\section{Characterizing the Steady State Before SBTC}

To examine the effects of SBTC, we assume that the economy is in steady state in the period preceding the shock, and characterize how investment, wages, and consumption are determined. In this initial steady state, let $\theta_{H}(t)=\theta_{H}$ and $\theta_{L}(t)=\theta_{L}$ for all $t$.

The assumption of constant survival probability simplifies the structure of the model in many ways. First, the optimality condition for investment choice (5) reduces to

$$
C_{j}^{\prime}\left(Q_{j}\right)=\frac{\theta_{H} \beta \delta}{1-\beta \delta}
$$

where the marginal benefit of investment is now constant, since the expected life span is now

\footnotetext{
${ }^{8}$ This assumption is not as restrictive as it might seem, since it can be satisfied by rescaling $l$ to a larger value. The theoretical results that follow do not depend on the particular value of $l$.
} 
independent of age. Using the functional form for the cost function we get

$$
Q_{j}=A_{j}\left(\frac{\alpha \delta \beta}{1-\beta \delta} \theta_{H}\right)^{\alpha /(1-\alpha)}
$$

where $A_{j} \equiv \widetilde{A}_{j}^{1 / 1-\alpha}$. The fact that $Q_{j}$ is independent of age implies that the human capital stock at age $s$ is simply $h_{j, s}=Q_{j}(s-1)$. Furthermore, this optimal investment choice satisfies the following equalities, which will be useful in our derivations below:

$$
C_{j}\left(Q_{j}\right)=\alpha C_{j}^{\prime}\left(Q_{j}\right) Q_{j}=\left(\frac{\alpha \delta \beta}{1-\delta \beta} \theta_{H}\right) Q_{j}
$$

This expression makes clear that the cost of investment evaluated at the optimal investment level depends on $j$ only through $Q_{j}$, implying that the subscript $j$ can be dropped from the cost function: $C_{j}\left(Q_{j}\right)=C\left(Q_{j}\right)$. The optimal amount of investment time, $i_{j, s}$, is given by the total cost of investment divided by potential earnings:

$$
i_{j, s}=\frac{C\left(Q_{j}\right)}{\theta_{L} l+\theta_{H} h_{j, s}}=\frac{\alpha \delta \beta}{1-\delta \beta} \times\left[\frac{\theta_{L} l}{\theta_{H} Q_{j}}+(s-1)\right]^{-1} .
$$

A few intuitive results can be seen from these expressions. First, equation (6) implies that individuals with higher ability make larger investments: $d Q_{j} / d A_{j}>0$. Second, even though individuals increase their human capital stock by a constant amount $Q_{j}$ every period, investment time falls with age: $d i_{j, s} / d s<0$. Third, equations (6) and (7) can be combined to show that $d i_{j, s} / d A_{j}>0$ : conditional on age, individuals with higher ability also devote a larger fraction of their time investing in human capital. Finally, and most importantly, the increase in investment time in response to SBTC is larger for individuals with higher ability: $d^{2} i_{j, s} / d \theta_{H} d A_{j}>0$. These results play a central role for the results that we prove below.

We are now ready to derive an expression for the average wage rate in the economy. In order to express the average wage in an easily interpretable form, it is convenient to define some new variables. Define the "average investment" in the economy:

$$
\bar{Q} \equiv \sum_{s=1}^{\infty} \mu(s) \int_{j} Q_{j} d j=\left(\frac{\alpha \delta \beta}{1-\delta \beta} \theta_{H}\right)^{\alpha /(1-\alpha)} E\left(A_{j}\right),
$$

the corresponding "average cost of investment":

$$
C(\bar{Q}) \equiv \sum_{s=1}^{\infty} \mu(s) \int_{j} C\left(Q_{j}\right) d j=\frac{\alpha \delta \beta}{1-\delta \beta} \theta_{H} \bar{Q},
$$


the "average human capital stock":

$$
H(\bar{Q}) \equiv \sum_{s=1}^{\infty} \mu(s) \int_{j} h_{j, s} d j=\sum_{s=1}^{\infty} \mu(s)(s-1) \times \int_{j} Q_{j} d j=\frac{\delta}{1-\delta} \bar{Q},
$$

and, finally, the "average raw labor endowment" in the economy:

$$
L \equiv \sum_{s=1}^{\infty} \mu(s) \int_{j} l d j=l
$$

Notice that $H(\bar{Q})$ and $L$ measure the aggregate human capital stock and raw labor, inclusive of on-the-job investment activities, which should not be confused with $H^{\text {net }}$ and $L^{\text {net }}$ defined earlier.

At a given point in time, $\bar{Q}$ and $C(\bar{Q})$ only depend on the future values of $\theta_{H}$, whereas the stock of human capital only depends on past levels of investment, which in turn is determined by the history of $\theta_{H}$ 's. ${ }^{9}$ Therefore, the former variables will adjust immediately in response to a permanent change in $\theta_{H}$ such as SBTC (making them "jump variables"), whereas $H(\bar{Q})$ will adjust only gradually (making it a "stock variable"). This distinction will play a crucial role in the analysis below.

Now, using the definition of an individual's wage in equation (1), the average wage rate in the economy can be calculated as

$$
\bar{w}=\int_{j, s} w_{j, s} \mu(s) d j d s=\left[\theta_{L} l+\theta_{H} H(\bar{Q})\right]-C(\bar{Q}) .
$$

By substituting the expressions for $H(\bar{Q})$ and $C(\bar{Q})$ we obtain

$$
\bar{w}=\theta_{L} l+\left(\frac{\delta}{1-\delta}-\frac{\alpha \delta \beta}{1-\delta \beta}\right) \theta_{H} \bar{Q}
$$

Optimal consumption choice.- Given the interest rate $r=1 /(\delta \beta)-1$, the optimal consumption path is constant over the life cycle, and is given by the fraction $(1-\delta \beta)$ of individuals' lifetime income. Then the average consumption in the economy is

$$
\bar{c}=\left[\theta_{L} l+\frac{\delta \beta}{1-\delta \beta} \theta_{H} \bar{Q}\right]-C(\bar{Q})=\theta_{L} l+\left((1-\alpha) \frac{\delta \beta}{1-\delta \beta}\right) \theta_{H} \bar{Q}
$$

Comparing the last two formulas, it is easy to see that average consumption is less than average wage $(\bar{c}<\bar{w})$ whenever $\beta<1$. The reason can be explained as follows. Given that the interest rate equals the reciprocal of the effective discount rate $(\delta \beta)$, individuals would like to maintain a

\footnotetext{
${ }^{9}$ As a result, the definition of $H(\bar{Q})$ in equation (10) is only valid in steady state when all past returns were constant. Similarly, the definitions of $\bar{Q}$ and $C(\bar{Q})$ are valid when all future returns are constant.
} 
constant consumption over their lifetime. But because all individuals have upward-sloping wage profiles, they need to borrow against their future income to maintain a constant consumption path. With a positive interest rate, part of aggregate labor income goes toward paying the interest that accrues on borrowed funds (which, for simplicity, is assumed to be borrowed from the rest of the world). Consequently, average consumption is less than the average wage in the economy.

\section{Characterizing the Behavior after SBTC}

In the following subsections, we consider a one-time permanent increase, at time $t^{*}$, in the price of human capital from $\theta_{H}$ to $\boldsymbol{\theta}_{H}^{\prime}$, while the price of raw labor, $\theta_{L}$, remains constant. ${ }^{10}$ We analyze the behavior of average wages (and labor productivity), the college premium, and overall wage inequality both in the short run and in the long run. For the short-run analysis, we focus our attention to the period immediately after the shock. Analyzing the economy in this time period captures the fact that, in the short run, the human capital stock does not fully adjust yet, but investment jumps to its new level immediately. Later in the quantitative analysis (Section 4), we model SBTC as a gradual change in the price of human capital that takes place over several years, and we show that the main conclusions drawn here remain valid.

\subsection{Stagnation of Average Wages (and the Slowdown in Labor Productivity)}

Labor economists and macroeconomists have documented two closely related trends during this period: the stagnation of median wage growth and the slowdown in labor productivity growth, which both started with a sharp fall in 1973 and persisted until about 1995. For example, the median real wage has increased by 2.2 percent per year between 1963 and 1973, but actually fell by 0.3 percent per year between 1973 and 1989 (Juhn, Murphy, and Pierce (1993)). Similarly, labor productivity (measured as the non-farm business output per hour) has grown by 2.6 percent per year from 1955 to 1973 , but only by 1.45 percent per year from 1973 to $1995 .{ }^{11}$

To develop the implications of the model, first consider the average wage in the economy in the initial steady state:

$$
\left.\bar{w}_{I} \equiv \bar{w}\right|_{t<t^{*}}=\left[\theta_{L} l+\theta_{H} \times H(\bar{Q})\right]-C(\bar{Q}) .
$$

As noted before, $\theta_{H}$ and $C(\bar{Q})$ increase immediately after SBTC, whereas $H(\bar{Q})$ adjusts only gradually. Therefore, the average wage immediately after SBTC (in the short run) is given by

$$
\left.\bar{w}_{S R} \equiv \bar{w}\right|_{t=t^{*}+\varepsilon}=\left[\theta_{L} l+\boldsymbol{\theta}_{H}^{\prime} \times H(\bar{Q})\right]-C\left(\overline{\mathbf{Q}}^{\prime}\right)
$$

\footnotetext{
${ }^{10}$ Since $\theta_{L}$ remains unchanged and $\theta_{H}$ increases, SBTC entails a true improvement in aggregate productivity in these experiments. An alternative way of modeling SBTC would be to assume that the rise in $\theta_{H}$ is matched by a symmetric fall in $\theta_{L}$. Almost all the results studied in the next section carry over to this case, and some of them become easier to prove. For example, the decline in average wage in the short run would be larger in this case. Similarly, consumption inequality would increase even less compared to wage inequality after SBTC. To show that these results do not follow trivially from the decline in $\theta_{L}$, we assume that $\theta_{L}$ is fixed and $\theta_{H}$ increases.

${ }^{11}$ Authors' calculation using data from the Bureau of Labor Statistics.
} 
where bold letters with a prime denote the values of variables in the final steady state. The stock of human capital, $H(\bar{Q})$, gradually increases to its new steady state value $H\left(\overline{\mathbf{Q}}^{\prime}\right)$, and the average wage in the new steady state is given by

$$
\left.\bar{w}_{L R} \equiv \bar{w}\right|_{t \rightarrow \infty}=\left[\theta_{L} l+\boldsymbol{\theta}_{H}^{\prime} \times H\left(\overline{\mathbf{Q}}^{\prime}\right)\right]-C\left(\overline{\mathbf{Q}}^{\prime}\right) .
$$

Price, Investment and Quantity Effects. - It is useful to decompose the changes in the average wage after SBTC into three components. First, using equations (14) and (15), the short-run response of the average wage can be written as

$$
\bar{w}_{S R}-\bar{w}_{I}=\underbrace{\left[\left(\boldsymbol{\theta}_{H}^{\prime}-\theta_{H}\right) \times H(\bar{Q})\right]}_{\text {Price Effect }(>0)}+\underbrace{\left[C(\bar{Q})-C\left(\overline{\mathbf{Q}}^{\prime}\right)\right]}_{\text {Investment effect }(<0)} .
$$

First, for a fixed stock of human capital, an increase in $\theta_{H}$ increases the wage rate. We call this the "price effect." Second, a higher $\theta_{H}$ also induces more investment, which reduces the wage rate by increasing the foregone earnings. We refer to this as the "investment effect." Therefore, the short-run response of the average wage is entirely determined by the relative strengths of these counteracting forces. In other words, whether or not the average wage falls in the short run depends on whether the investment effect dominates the price effect. Below we examine the conditions under which this outcome obtains.

Similarly, using equations (15) and (16) we have

$$
\bar{w}_{L R}-\bar{w}_{S R}=\underbrace{\boldsymbol{\theta}_{H}^{\prime} \times\left(H\left(\overline{\mathbf{Q}}^{\prime}\right)-H(\bar{Q})\right)}_{\text {Quantity Effect }(>0)},
$$

which shows that the only change between the short run and the long run is the (slow) adjustment of the human capital stock. We call this long-run channel the "quantity effect." Finally, adding up equations (17) and (18) shows that the total effect of SBTC on the average wage $\left(\bar{w}_{L R}-\bar{w}_{I}\right)$ can simply be written as the sum of the price, investment, and quantity effects. We will use analogous decompositions to examine the effect of SBTC on other variables below, where the main idea will be the same as here.

Before we can state the main result of this section, we need the following condition, which characterizes the parameter values under which the investment effect dominates the price effect.

Condition $1 \frac{\alpha \delta \beta}{(1-\delta \beta)(1-\alpha)}>\frac{\delta}{1-\delta}$. 
Figure 2: The Parameter Combinations $(\alpha, r)$ in the Shaded Region Imply Condition 1

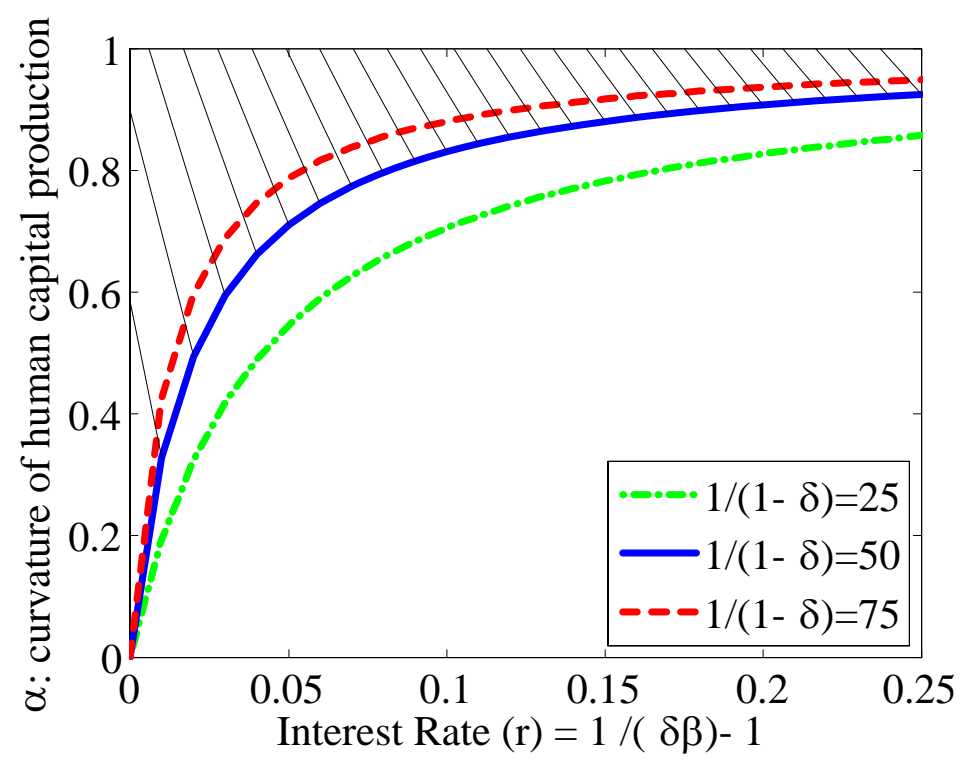

Figure 2 illustrates the parameter combinations that satisfy condition 1 . From equation (17), it is clear that the investment effect would dominate the price effect if either the initial stock of human capital is low so that the price effect is small, or the response of investment is high. The latter is, in turn, mainly determined by two parameters. First, the response of investment to SBTC is larger when $\alpha$ is high. This is because, as noted earlier, a higher $\alpha$ implies less diminishing marginal returns in human capital production. Consequently, there is little benefit from spreading investment over time (as would be the case if $\alpha$ were low.) Second, for a given $(\alpha, \delta)$, a higher $\beta$ makes the present discounted value of future wages larger, implying a higher benefit from a given increase in the price of human capital. Thus, the response of investment to SBTC increases with $\beta$ (and the corresponding low interest rate). At the same time, the stock of human capital is increasing in the survival probability, so the price effect is more likely to dominate the investment effect when $\delta$ is large. ${ }^{12}$ The combination of these three forces gives rise to the the region of admissible parameters shown in Figure 2. This region contains a fairly wide range of plausible parameter combinations. For example, assuming an expected working life of 50 years and an interest rate of 5 percent, any curvature value above 0.71 satisfies condition 1 . Estimates of this parameter are typically around 0.8 and higher (see, for example, Heckman (1976), and more recently, Heckman, Lochner, and Taber (1998) and Kuruscu (2006)). The following proposition characterizes the behavior of average wages.

\footnotetext{
${ }^{12}$ It should be stressed that all three parameters affect both the price and investment effects (which can be seen from equations $(8,9,10)$. So the discussion here, for example, of the impact of $\alpha$ on the cost of investment only highlights the stronger of the two effects it has (even though it affects both the price and investment effects).
} 
Proposition 1 (Stagnation of Average Wages) In response to $S B T C$, for all $\boldsymbol{\theta}_{H}^{\prime}>\theta_{H}$, the average wage (alternatively, labor productivity)

1. increases in the long run, i.e., $\bar{w}_{L R}>\bar{w}_{I}$.

2. falls in the short run, i.e., $\bar{w}_{S R}<\bar{w}_{I}$, if condition 1 holds.

Proof. See Appendix A for all the omitted proofs and derivations.

It should be emphasized that for a marginal increase in $\theta_{H}$, condition 1 is not only sufficient but also necessary for the average wage to decline in the short run. However, if the increase in the price of human capital is larger, the average wage would decline under a weaker condition, making condition 1 sufficient but not necessary in general.

The transition path of the average wage after SBTC is easy to characterize: since the stock of human capital increases monotonically over time, it can be seen (by comparing equations (15) and (16)) that after the initial decline the average wage also increases monotonically over time. Furthermore, different measures of the length of this transition can be computed explicitly (proofs in the appendix).

Corollary 1 After the initial decline, the average wage increases monotonically to its new steady state level. The time it takes for the average wage to complete half of the transition toward the new steady state, $w_{t_{1}}=w_{S R}+\left(w_{L R}-w_{S R}\right) / 2$, is given by $t_{1}=-\log 2 / \log \delta$.

See the appendix for the derivation of $t_{1}$. Notice that the half-life of the transition depends only on the survival probability, which determines the average age in the economy. In particular, when the population is young on average ( $\delta$ is small) the transition is faster. Loosely speaking, in this case individuals born before SBTC (who invested at a lower rate for years) are replaced more quickly with younger generations, which increases the average human capital stock more quickly.

For plausible parameter values the transition could be quite slow: for $\delta=0.98$ (average working life of 50 years), $t_{1}=35$ years, and for $\delta=0.96$ (average working life of 25 years), $t_{1}=17$ years. However, note that these numbers do not necessarily imply that the average wage will stay below its initial steady state value for this long. An alternative measure of convergence speed is the time it takes for the wage to return to its level before the shock (formula reported in Appendix A; see equation (28)). For $\beta=\delta=0.98$ and assuming an increase in $\theta_{H}$ of 50 percent implies that the average wage stays below its initial level for 21 years. If $\beta=\delta=0.96$, the corresponding duration is 11 years. Overall, these back-of-the-envelope calculations suggest that the average wage can stagnate below its initial level for a decade or perhaps longer, and the convergence to the final steady state is likely to be even slower. We return to the speed of transition again in Section 4. 
Finally, there would be no stagnation in average wages without the endogenous response of investment to SBTC. Thus, the human capital response is essential for these results. The following corollary states this.

Corollary 2 If individuals' investment behavior did not respond to $S B T C$ (i.e., $\mathbf{Q}_{j, s}^{\prime}=Q_{j, s}$ for all $j, s$ ) the average wage would immediately jump after SBTC from its initial steady state value to final steady state value.

\subsection{Between-Group Wage Inequality (College Premium)}

The wages of college graduates declined throughout the 1970s relative to the wages of less-educated individuals. Starting in the early 1980s this trend reversed course, and the college premium increased sharply in the subsequent two decades. For example, the average male college graduate earned 52 percent more than a high-school graduate in 1970; this premium fell to 41 percent in 1979 and increased back to 84 percent by 2000 (Autor, Katz, and Kearney (2005a)). In this section, we characterize the behavior of the college premium in the model. We show that under condition 1, SBTC leads to a non-monotonic change in the college premium similar to that observed in the data.

Consistent with the standard interpretation of the Ben-Porath model, the perspective adopted in this paper is that educational labels merely represent some threshold level for the human capital investment completed. Thus, a "college graduate" is defined as an individual who has invested above a certain threshold in a specified number of periods. ${ }^{13}$ Since there is a one-to-one relationship between investment time and ability at every age, there is a corresponding threshold ability level above which all individuals $\left(A_{j}>A_{j^{*}}\right)$ become college graduates. However, notice that this threshold depends on the price of human capital and will therefore change in response to SBTC. In the following, we abstract from these changes in $A_{j^{*}}$. This approach is consistent with how the changes in the college premium have typically been measured in empirical studies (cf., Katz and Murphy (1992)). This is because allowing for changes in $A_{j^{*}}$ would affect the ability composition of each education group over time, thereby potentially confounding the effects of changes in the premium on education with changes in the returns to ability. Hence, as in empirical work, we fix the ability distribution of each group and analyze how their wages change in response to SBTC.

Let $\bar{Q}_{c}$ and $E_{c}[A]$ denote the average investment and average ability of college graduates, respectively. We define $\bar{Q}_{n}$, and $E_{n}[A]$ in an analogous fashion for individuals without a college degree. From the discussion above, it is clear that $E_{c}[A]>E_{n}[A]$, which also implies $\overline{Q_{c}}>\bar{Q}_{n}$

\footnotetext{
${ }^{13}$ More formally, the condition can be stated as $\sum_{s=1}^{\widetilde{s}} 1\left\{i_{j, s}>i^{*}\right\} \geq S_{c}$, where $i^{*}$ is the investment time threshold (which is equal to 1 in the standard Ben-Porath model), $\widetilde{s}$ is the individual's current age, and $S_{c}$ is the number of years of schooling required to qualify as a college graduate.
} 
from equation (8). Finally, let $\bar{w}_{c}$ (alternatively $\bar{w}_{n}$ ) be the average wage of college (high school) graduates. Then, the college premium before SBTC is

$$
\left.\omega_{I}^{*} \equiv \frac{\bar{w}_{c}}{\bar{w}_{n}}\right|_{t<t^{*}}=\frac{\theta_{L} l+\theta_{H} H\left(\bar{Q}_{c}\right)-C\left(\bar{Q}_{c}\right)}{\theta_{L} l+\theta_{H} H\left(\bar{Q}_{n}\right)-C\left(\bar{Q}_{n}\right)} .
$$

The college premium in the short run (that is, immediately after SBTC) is given by

$$
\left.\omega_{S R}^{*} \equiv \frac{\bar{w}_{c}}{\bar{w}_{n}}\right|_{t=t^{*}+\varepsilon}=\frac{\left[\theta_{L} l+\boldsymbol{\theta}_{H}^{\prime} H\left(\bar{Q}_{c}\right)\right]-C\left(\overline{\mathbf{Q}}_{c}^{\prime}\right)}{\left[\theta_{L} l+\boldsymbol{\theta}_{H}^{\prime} H\left(\bar{Q}_{n}\right)\right]-C\left(\overline{\mathbf{Q}}_{n}^{\prime}\right)} .
$$

In the long run, the premium is given by

$$
\left.\omega_{L R}^{*} \equiv \frac{\bar{w}_{c}}{\bar{w}_{n}}\right|_{t \rightarrow \infty}=\frac{\left[\theta_{L} l+\boldsymbol{\theta}_{H}^{\prime} H\left(\overline{\mathbf{Q}}_{c}^{\prime}\right)\right]-C\left(\overline{\mathbf{Q}}_{c}^{\prime}\right)}{\left[\theta_{L} l+\boldsymbol{\theta}_{H}^{\prime} H\left(\overline{\mathbf{Q}}_{n}^{\prime}\right)\right]-C\left(\overline{\mathbf{Q}}_{n}^{\prime}\right)} .
$$

The following proposition characterizes the behavior of the college premium (proof in the appendix).

Proposition 2 (Behavior of College Premium) In response to $S B T C$, for all $\boldsymbol{\theta}_{H}^{\prime}>\theta_{H}$, the college premium

(i) rises in the long run, i.e., $\omega_{L R}^{*}>\omega_{I}^{*}$,

(ii) falls in the short run, i.e., $\omega_{S R}^{*}<\omega_{I}^{*}$, if condition 1 holds.

Despite the similarities between the statements of propositions 1 and 2 , there is an important difference between the two. While the stagnation of average wages only requires the endogenous response of human capital investment to SBTC (i.e., that $C(Q)$ increases after the shock), the fall in the college premium requires, in addition, that this response be different across education groups. In other words, if heterogeneity in ability was eliminated from the model, average wages would still stagnate after SBTC, but the college premium would not fall in the short run. ${ }^{14}$

Since college graduates accumulate skills faster than high school graduates, the college premium increases monotonically toward the new steady state value after the initial fall. Moreover, it can be easily shown that the response of the college premium is proportional to the ability differential between college and high school graduates.

\footnotetext{
${ }^{14}$ It should be clear from this discussion that one can prove a result analogous to corollary 2 for the college premium: if individuals' investment did not respond to SBTC, the college premium would immediately jump from its initial steady state to its final steady state value.
} 
Corollary 3 In response to SBTC, the decline (increase) in the college premium in the short run (long run) is larger, when the ability differential between college graduates and high school graduates, $E_{c}[A] / E_{n}[A]$, is larger.

Decomposing the College Premium.-To understand the behavior of the college premium further, an intuitive discussion is helpful. For the sake of this discussion, assume that there are no differences in ability within each education group, and the investment levels are denoted by $Q_{c}$ and $Q_{n}$ for college and non-college groups, respectively. However, investment time will vary within each education group due to differences in age, and hence, in potential earnings. Using the expression for investment time in (7), we can rewrite the college premium as

$$
\omega^{*}=\frac{\theta_{L} l+\theta_{H} H\left(Q_{c}\right)}{\theta_{L} l+\theta_{H} H\left(Q_{n}\right)} \times \frac{1-\overline{i_{c}}}{1-\overline{i_{n}}}=\underbrace{\frac{l+\left(\theta_{H} / \theta_{L}\right) H\left(Q_{c}\right)}{l+\left(\theta_{H} / \theta_{L}\right) H\left(Q_{n}\right)}}_{G_{1}} \times \underbrace{\frac{1-\overline{i_{c}}}{1-\overline{i_{n}}}}_{G_{2}},
$$

where all the variables that appear in this expression are defined as before, but the averages are now taken with respect to the group indicated by the subscript. ${ }^{15}$

The first term in the decomposition, $G_{1}$, captures the price and quantity effects of changes in $\theta_{H}$. Both of these effects are larger for college graduates because they have a larger human capital stock, and moreover, their human capital stock increases more after SBTC (though the latter happens only gradually). The key point to note is that there is no reason for $G_{1}$ to behave in any way other than increase monotonically after SBTC. If there was no investment response in the model, $G_{2}$ would be constant over time and the college premium would be proportional to $G_{1}$ and would also increase monotonically.

The differential investment response captured by $G_{2}$ is thus crucial for the initial decline in the college premium. There are two reasons for the initial decline in $G_{2}$. First, after SBTC college graduates increase their investment time more than high school graduates. In the long run, this follows from the fact that $d^{2} i_{j, s} / d \theta_{H} d A_{j}>0$ mentioned above. The same can be shown to be true in the short run. ${ }^{16}$ A second and reinforcing effect responsible for the fall in $G_{2}$ is that the initial level of investment time is larger for college graduates. As a result, even the same amount of increase in investment time would cause a decline in $\left(1-\bar{i}_{c}\right) /\left(1-\bar{i}_{n}\right)$. Overall, then, the college premium falls initially because $G_{2}$ (which depends on the jump variables, $\bar{i}_{c}$ and $\bar{i}_{n}$ ) falls quickly, but then recovers as $G_{1}$ gradually increases over time.

\footnotetext{
${ }^{15} \bar{i}_{c}$ is the average investment time of college graduates, which is calculated as the ratio of each individual's potential earnings $\left(\theta_{L} l+\theta_{H} Q_{c}(s-1)\right)$ to average potential earnings of that group $\left(\theta_{L} l+\theta_{H} \frac{\delta}{1-\delta} \bar{Q}_{c}\right)$ as weights. $\bar{i}_{n}$ is defined analogously.

${ }^{16}$ More formally, we evaluate how the increase in investment time changes with $A$ : we calculate $d^{2} i / d A d \boldsymbol{\theta}_{H}^{\prime}$, which equals a positive constant times $\theta_{L} l+(2 \alpha-1) \frac{\delta}{1-\delta} \boldsymbol{\theta}_{H}^{\prime} \bar{Q}$. It is clear that $\alpha>0.5$ is a sufficient condition for this cross-partial to be positive. When $\alpha<0.5$, this will still hold true if $\theta_{L} l /\left(\frac{\delta}{1-\delta} \boldsymbol{\theta}_{H}^{\prime} \bar{Q}\right)$ is large enough.
} 


\subsubsection{College Premium Within Age Groups}

A well-documented fact is that the behavior of the college premium in the United States during this period has been different for different experience groups (see Katz and Murphy (1992) and Murphy and Welch (1992)). In particular, these authors show that the fall and rise in the overall college premium were largely attributable to this behavior among individuals with less experience. In contrast, the fall and rise in the premium among more experienced individuals have been very much muted. Similarly, Card and Lemieux (2001) focus on age groups (rather than experience), and examine data from the United Kingdom and Canada in addition to the United States. They find the same pattern to emerge in these countries as well.

To examine this issue, we now look at the college premium among $s$-year-old individuals, which is given in the first steady state by

$$
\omega_{I}^{*}(s)=\frac{\theta_{L} l+\theta_{H} \bar{Q}_{c}(s-1)-C\left(\bar{Q}_{c}\right)}{\theta_{L} l+\theta_{H} \bar{Q}_{n}(s-1)-C\left(\bar{Q}_{n}\right)} .
$$

Similarly, the premium in the short run and in the long run after SBTC is defined analogously to equations (19) and (20).

Proposition 3 (Behavior of College Premium Within Age Groups) Define $\underline{s}=1+\frac{\alpha \delta \beta}{1-\delta \beta}$ and $\bar{s}=1+\frac{\alpha \delta \beta}{(1-\delta \beta)(1-\alpha)}$. Then in response to $S B T C$, for all $\boldsymbol{\theta}_{H}^{\prime}>\theta_{H}$, the college premium among s-year-old individuals

(i) falls in the short run, $\omega_{S R}^{*}(s)<\omega_{I}^{*}(s)$, if and only if $s<\bar{s},{ }^{17}$

(ii) rises in the long run, $\omega_{L R}^{*}(s)>\omega_{I}^{*}(s)$, if and only if $s>\underline{s}$.

An important difference of this proposition from the previous one is that here the decline in the college premium for young individuals does not require condition 1 , and therefore, holds under more general conditions than proposition 2. Furthermore, from proposition 3 , it is also easy to conjecture that whether the average college premium falls in the short run will depend on whether there are sufficiently many young individuals in the population. In fact, this is exactly what condition 1 in proposition 2 ensures: the condition that the average age in the population be less than $\bar{s}$ (that is, $1 /(1-\delta)<\bar{s})$ is exactly the same as condition 1 .

Proposition 3 partitions the population into three age groups, where the college premium displays distinct behaviors (shown in Table 1). To explain the intuition for these results, it is convenient

\footnotetext{
${ }^{17}$ The necessity part of the proposition (the "only if" part) applies for a marginal increase in $\theta_{H}$. For larger increases, $s<\bar{s}$ is a sufficient condition for the college premium to decline, but not a necessary condition. The same comment applies to part (ii) of the proposition. The reason we consider this stronger form of the proposition is because it allows us to divide the age range into three distinct groups in table 1 below.
} 
Table 1: Evolution of College Premium Within Age Groups After SBTC

\begin{tabular}{lccc}
\hline \hline & \multicolumn{3}{c}{ College premium within $s$-year-old individuals: } \\
\hline If s satisfies: & $\mathbf{s} \leq \underline{s}$ & $\underline{s}<\mathbf{s}<\bar{s}$ & $\bar{s} \leq \mathbf{s}$ \\
\hline Short run: & Declines & Declines & Increases \\
$\log \left(\omega_{S R}^{*}(s) / \omega_{I}^{*}(s)\right)$ & $(<0)$ & $(<0)$ & $(>0)$ \\
\hline Long run: & Declines & Increases & Increases \\
$\log \left(\omega_{L R}^{*}(s) / \omega_{I}^{*}(s)\right)$ & $(<0)$ & $(>0)$ & $(>0)$ \\
\hline
\end{tabular}

Notes: See proposition 3 for the definitions of $\underline{s}$ and $\bar{s}$. The table displays the behavior of the college premium for a marginal increase in $\theta_{H}$.

to take a first-order Taylor series approximation to the college premium for $s$-year-old individuals (in the initial steady state, short run, and long run), which yields

$\log \left(\frac{\omega_{S R}^{*}(s)}{\omega_{I}^{*}(s)}\right) \approx \underbrace{\left[\left(\boldsymbol{\theta}_{H}^{\prime}-\theta_{H}\right) \times\left(\bar{Q}_{c}-\bar{Q}_{n}\right)(s-1)\right]}_{\text {Differential Price Effect }(>0)}+\underbrace{\left[\left(C\left(\bar{Q}_{c}\right)-C\left(\overline{\mathbf{Q}}_{c}^{\prime}\right)\right)-\left(C\left(\bar{Q}_{n}\right)-C\left(\overline{\mathbf{Q}}_{n}^{\prime}\right)\right)\right]}_{\text {Differential Investment Effect }(<0)}$,

and

$$
\log \left(\frac{\omega_{L R}^{*}(s)}{\omega_{S R}^{*}(s)}\right) \approx \underbrace{\boldsymbol{\theta}_{H}^{\prime} \times\left[\left(\overline{\mathbf{Q}}_{c}^{\prime}-\bar{Q}_{c}\right)-\left(\overline{\mathbf{Q}}_{n}^{\prime}-\bar{Q}_{n}\right)\right](s-1)}_{\text {Differential Quantity Effect }(>0)}
$$

(up to a constant scaling factor). Adding up these two equations shows that the total change in $\log$ education premium, $\log \left(\omega_{L R}^{*}(s) / \omega_{I}^{*}(s)\right)$, is simply given by the sum of the price, investment, and quantity effects. Comparing these last two equations to their counterparts derived earlier for the average wage (equations (17) and (18)), we note that the only change here is the appearance of "double differences." For example, the price effect here results from the differential impact of the increase in $\theta_{H}$ on the human capital stocks of college and non-college workers. The same goes for investment and quantity effects. However, inspecting these two equations also shows that the three effects have the same signs on the college premium as they had on the average wage. This is because college workers have higher ability on average, and therefore (i) they have a larger human capital stock before the shock (resulting in a positive price effect), (ii) they increase their investment by more after the shock (negative investment effect), and (iii), in the long run they experience a larger increase in their human capital stock (positive quantity effect).

To understand the behavior of the college premium among different age groups, two points should be noted. First, the price and investment effects on the college premium increase with agenotice the multiplicative $(s-1)$ terms that appear in these two effects - whereas the investment effect does not vary with age. Therefore, in the short run the constant investment effect dominates 
the price effect for younger individuals, but not for older ones who experience a larger price effect $(\mathbf{s} \geq \bar{s})$. The formal proof in the appendix establishes that $\bar{s}>1$, so that the college premium does fall among a group of young individuals in the short run, but not for the old. Second, as before, the only difference of long run is the additional quantity effect. As a result, some of the relatively younger individuals $(\underline{s}<\mathbf{s}<\bar{s})$ also experience a rise in the premium, and only the very young see a decline in the long run. ${ }^{18}$

\subsection{Overall Wage Inequality}

As mentioned earlier, the movement of overall inequality and between-group inequality in opposite directions in the 1970s has received much attention in the literature. In this section we analyze the behavior of overall wage inequality in response to SBTC both in the short run and in the long run. We show that under a simple sufficient condition, overall inequality rises in the short run. Together with the fact that the college premium falls in the short run under condition 1, this shows that the present model is consistent with the joint behavior of college premium and overall wage inequality. ${ }^{19}$

To this end, first, the cross-sectional variance of wages can be shown to be

$$
\operatorname{Var}(w)=\left(n_{1} \operatorname{Var}(A)+n_{2} E[A]^{2}\right) \times \theta_{h}^{2 /(1-\alpha)},
$$

where the coefficients $n_{i}$ 's are all positive in the rest of the text (the exact expressions are provided in Appendix A). In order to eliminate the effect of the levels of variables on measures of inequality, we focus on the coefficient of variation of wages, which we denote by $C V(w)$. It is given by

$$
C V(w) \equiv \frac{S t d(w)}{\bar{w}}=\frac{\left[n_{1} \operatorname{Var}(A)+n_{2} E[A]^{2}\right]^{1 / 2}}{\frac{\theta_{L} l}{\theta_{H}^{1 /(1-\alpha)}}+n_{4} E[A]}
$$

This expression shows that wage inequality is driven by two sources. First, heterogeneity in learning ability (captured by $\operatorname{Var}(A)$ ) creates wage differences within every age group, and therefore increases wage inequality. Second, a higher average learning ability $(E[A])$ generates more wage growth over the life cycle - and hence wage differences across age groups - thereby increasing the variance in the numerator; but it also increases the average wage, thereby increasing the denominator. Consequently, the effect of average ability on inequality is ambiguous, whereas the effect of ability heterogeneity on inequality is always positive.

\footnotetext{
${ }^{18}$ Moreover, among these very young individuals, those with high ability earn less than those with low ability. This is consistent with the evidence from panel data sets such as PSID, where starting wages and wage growth rates over the life cycle are negatively correlated (cf., Lillard and Weiss (1979), Baker (1997), and Guvenen (2005a) among others).

${ }^{19}$ It is possible to show that within-group inequality also rises in the long run after SBTC. We omit this result from the main text for brevity, but we present the main proposition and its proof in Appendix B for completeness.
} 
The expression in (24) shows that the coefficient of variation is increasing in $\theta_{H}$, implying that, compared to the initial steady state, wage inequality will be higher in the new steady state after SBTC. In fact, this result could be anticipated from figure 1, which shows both the widening of the wage distribution within age groups, and the steepening of profiles across age groups when $\theta_{H}$ is higher.

Finally, it is also possible to derive a (complicated) expression for the coefficient of variation of wages immediately after SBTC (i.e., in the short run) and prove the following result:

Proposition 4 (Rise in Overall Wage Inequality) In response to $S B T C$, for all $\boldsymbol{\theta}_{H}^{\prime}>\theta_{H}$, wage inequality (as measured by the coefficient of variation):

1. increases in the long run, i.e., $C V_{L R}(w)>C V_{I}(w)$,

2. also increases in the short run, i.e., $C V_{S R}(w)>C V_{I}(w)$, if $\beta=1$.

The proof is in Appendix A. While $\beta=1$ is sufficient for an increase in wage inequality in the short run, it is far from being necessary. When $\beta<1$, there is still a wide range of parameters resulting in an increase in wage inequality in the short run, though we have not been able to find a simple sufficient condition in that case.

When taken together, propositions 2 and 5 show that overall wage inequality and betweengroup inequality (college premium) move in opposite directions in the short run after SBTC. As noted earlier, this result is consistent with evidence from the U.S. data, and the present framework delivers this outcome despite being a one-skill model.

An important reason for the rise in overall inequality - despite a falling college premium - is that in the short run, average wage profiles shift downward and become steeper, increasing the wage differences between the young and the old. To see this, consider the average wage of individuals at age $s$ immediately after SBTC:

$$
\bar{w}_{S R}(s)=\left[\theta_{L} l+\boldsymbol{\theta}_{H}^{\prime}(\bar{Q}(s-1))\right]-C\left(\overline{\mathbf{Q}}^{\prime}\right) .
$$

Notice that $\bar{Q}(s-1)$ is the stock of human capital of $s$-year-old individuals and is thus relatively fixed in the short run. As mentioned earlier, the price effect is larger for older individuals who have a higher human capital stock compared to younger individuals. This differential price effect steepens the wage profiles immediately after SBTC. Second, the investment effect, $C\left(\overline{\mathbf{Q}}^{\prime}\right)$, is independent of age, so it reduces the level of wages for all age groups by the same amount, which shifts the experience profile of wages downward, and therefore, increases percentage differences between the young and the old. In turn, this further increases inequality (as measured by the coefficient of variation) across different age groups. As a result, overall wage inequality will increase - despite a fall in college premium-because of a steepening age profile of wages. The steepening of wage 
profiles after SBTC is consistent with the U.S. data: Katz and Murphy (1992, Table 1) report that the wages of workers with 1-5 years of experience fell by 10.2 percent compared to workers with 26-35 years of experience between 1971 and 1987.

\subsubsection{Wage Inequality and Consumption Inequality}

The measures of wage inequality discussed so far (i.e., overall and between-group) relate to the distribution of wages at a point in time. In that sense, they provide some "snapshot" measures of inequality. For many purposes, however, it is of interest to know whether the observed changes in these snapshots imply a parallel change in lifetime income inequality.

A somewhat surprising relevant empirical finding is that the rise in consumption inequality has been muted compared to the rise in wage inequality during this period. Although there remains some disagreement about the exact magnitude of the rise in consumption inequality (mainly due to data problems), several authors report findings broadly supporting this conclusion (see, for example, Krueger and Perri (2006) and Attanasio, Battistin, and Ichimura (2004)). Moreover, the change between the 90th and 50th percentiles of the consumption distribution has not tracked the large rise in the 90-50 percentile wage differences. Autor, Katz, and Kearney (2004) document this fact and find it puzzling.

We now examine the behavior of lifetime wage income inequality in response to SBTC. Note that under the assumptions made so far, individuals choose a constant consumption path over their life cycle. As a result, consumption inequality equals lifetime wage inequality and we use the two interchangeably. First it can be shown (see Appendix A) that the variance of consumption equals

$$
\operatorname{Var}(c)=n_{3} \operatorname{Var}(A) \theta_{h}^{2 /(1-\alpha)} .
$$

This expression differs from the one for the variance of wages (equation (23)) in two ways. First, as noted earlier, part of the variance of wages is due to the differences in wages across age groups (when $(E(A)>0)$ ). This effect is not present in the variance of consumption, because individuals with the same ability will consume the same amount regardless of their age, since they have the same lifetime income. Therefore, the variance of consumption is driven by heterogeneity in learning ability, which is the only source of permanent differences in lifetime incomes. Second, a given heterogeneity in learning ability $(\operatorname{var}(A))$ results in smaller consumption inequality than wage inequality (i.e., $n_{3}<n_{1}$, which can be shown easily). The intuition for this result is that those individuals who have high wages later in life are exactly those who make larger investments and accept lower wages early on. Therefore, consumption inequality is always lower than cross-sectional wage inequality in steady state.

We now use these results to examine how wage and consumption inequality change relative to each other in response to SBTC. In particular, when the subjective time discount rate is zero, we 
can show that $C V(w)^{2}$ will always increase more than $C V(c)^{2}$ in response to SBTC, regardless of other parameter values. The next proposition states this result.

Proposition 5 (Rise in Wage and Consumption Inequality) Assume that $\beta=1$. In response to $S B T C$, for all $\boldsymbol{\theta}_{H}^{\prime}>\theta_{H}$, wage inequality rises more than consumption inequality in the long run, i.e., $C V_{L R}(w)^{2}-C V_{I}(w)^{2}>C V_{L R}(c)^{2}-C V_{I}(c)^{2}$.

To prove this proposition, note that when $\beta=1$, we have $\bar{c}=\bar{w}$ (using equations (12), and (13)). Then combining equations (12), (23) and (25), we have

$$
C V(w)^{2}-C V(c)^{2}=\frac{n_{2}\left(\operatorname{Var}(A)+E[A]^{2}\right)}{\left\{\frac{\theta_{L} l}{\theta_{H}^{1 /(1-\alpha)}}+n_{4} E[A]\right\}^{2}},
$$

in a given steady state. It is easy to see that this expression is increasing in $\theta_{H}$. Therefore, it is higher in steady state after SBTC than in the initial steady state, which completes the proof.

Note that the difference between wage and consumption inequality increases more with an increase in $\theta_{H}$ when $\operatorname{var}(A)$ is larger. Furthermore, if SBTC is modeled as involving a simultaneous fall in $\theta_{L}$, then the difference between wage and consumption inequality would increase even further after SBTC. Although we have not been able to extend this result to the more general case with $\beta<1$, in the quantitative analysis we have found wage inequality to increase (substantially) more than consumption inequality for a wide range of parameter values.

Finally, the fact that lifetime inequality changes little does not mean that the welfare implications of SBTC are unimportant. This is because SBTC has a significant effect on the growth rate of average wages that are realized decades after the onset of SBTC. For example, economies that try to reduce inequality after SBTC by compressing the wage structure, say through progressive taxation or increased unionization (which then penalize human capital accumulation), would have lower growth in decades after SBTC.

\section{Quantitative Analysis}

A full quantitative analysis of this model would require introducing several important features that have been assumed away for technical convenience, and is therefore beyond the scope of this paper. Nevertheless, it is useful to provide a simple (illustrative) calibration of the model to gain some idea about its general behavior. To carry out this exercise, we make some minimal necessary changes to the theoretical model as described below. 


\subsection{Calibration}

We assume that individuals enter the model at age 20 and retire at $65(T=45)$, relaxing the perpetual youth assumption made before. The interest rate is set equal to 0.05 , and the subjective time discount rate is set to $\beta=1 /(1+r)$, implying that individuals will choose a constant consumption path over their life cycle.

Aggregate Production Function.-The growth rate of neutral technology level, $Z$, is set equal to 1.5 percent per year. As will become clear below, measured TFP growth will be different than this number when the amount of investment on-the-job changes over time. Since $\theta_{L}$ and $\theta_{H}$ always appear multiplicatively with labor and human capital, the initial values of these parameters serve only as a normalization (given that $H$ and $L$ are also going to be calibrated below). Therefore, we normalize $\theta_{L, t}+\theta_{H, t}=1$ and set $\theta_{L, t}=\theta_{H, t}=0.5$ for all $t<1970$. The change in the skill bias of technology, $\theta_{H, t} / \theta_{L, t}$, after 1970 is calibrated later below.

Human Capital Accumulation.-In the previous section we assumed that individuals could invest any fraction of their time while working on the job as in the standard Ben-Porath model. However, with a continuum of ability levels, this implies that there will be some individuals who invest slightly less than 100 percent of their time, appearing as employed earning a wage income very close to zero. Because many of the statistics we analyze below involve the logarithm of wage rates as well as the variances of these logarithms, even a small number of such individuals can easily wreak havoc with the quantitative exercise. One way to circumvent this difficulty is to impose an upper bound on the choice of $i_{s}$ while on the job. In particular, the choice set for investment time is now $i_{s} \in[0, \chi] \cup\{1\}$, where $\chi<1$ denotes the maximum on-the-job human capital investment possible. ${ }^{20}$ We calibrate $\chi$ to 0.50 , which implies that the lowest wage earned in the economy before SBTC is about 70 percent of the average wage. The curvature of the human capital accumulation function, $\alpha$, is set to 0.8 , which is consistent with the range of estimates obtained in the literature (cf., Heckman (1976), Heckman, Lochner, and Taber (1998), and Kuruscu (2006)).

The remaining parameters of the model will be chosen to match some empirical moments of the U.S. wage distribution. To this end, it is first important to account for idiosyncratic shocks to wages, which are absent from the model but are clearly present in the data. In a companion paper we show that under some assumptions ${ }^{21}$ the existence of persistent and transitory idiosyncratic wage shocks (i) will affect the level of the variance of wages, but not its trend, and (ii) will not affect the level of the first moment of wages. Therefore, in the comparisons below we only need to adjust the level of the empirical variance of wages, but not the levels of the first moments. See Guvenen and Kuruscu (2006) for more details.

\footnotetext{
${ }^{20}$ This upper bound could arise, for example, if the firm incurs fixed costs for employing each worker (administrative burden, the cost of office space, supplies, etc.), or due to minimum wage laws. The model with this extension can still be solved in closed form.

${ }^{21}$ Briefly, we assume that the wages observed in the data can be written as $\widetilde{w}_{s, t}^{i}=\widehat{w}_{s, t}^{i}+v_{s, t}^{i}+\varepsilon_{s, t}^{i}$, where $\widehat{w}_{t}^{i}$ denotes the systematic component determined by the human capital model; $v_{s, t}^{i}$ and $\varepsilon_{s, t}^{i}$ represent an $\mathrm{AR}(1)$ and an
} 
Table 2: Baseline Parameterization

\begin{tabular}{clr}
\hline Parameter & \multicolumn{1}{c}{ Value } \\
\hline$r$ & Interest rate & 0.05 \\
$\beta$ & Time discount rate & $1 /(1+r)$ \\
$\alpha$ & Curvature of human capital function & 0.80 \\
$T$ & Years spent in the labor market & 45 \\
$\chi$ & Maximum investment on the job & 0.50 \\
$\Delta Z$ & Growth rate of neutral technology & 0.015 \\
$l$ & labor endowment (scaling) & 1.0 \\
\hline Parameters calibrated to match 1965-69 targets: & .071 \\
\hline$E\left[\widetilde{A}_{j}\right]$ & Average ability & .247 \\
$\sigma\left[\widetilde{A}_{j}\right] / E\left[\widetilde{A}_{j}\right]$ & Coefficient of variation of ability \\
\hline Parameter calibrated to match 1995 wage inequality: & $2.3 \%$ \\
\hline$\Delta\left(\theta_{H} / \theta_{L}\right)$ & Annual change in skill-bias (1970 to 1995) \\
\hline
\end{tabular}

The value of raw labor, $l$, is a scaling parameter and is normalized to one. Learning ability, $\widetilde{A}_{j}$, is assumed to be uniformly distributed in the population with the same parameters for every cohort. We choose the mean and standard deviation of this distribution so that the model matches some key moments of the data in the first steady state. In particular, the targets are the average values between 1965 and 1969 of (i) the cross-sectional variance of log wages, (ii) the level of the log college premium, and (iii) the average wage growth over the life cycle.

The target value of cross-sectional variance of wages is 0.105 after adjusting for the absence of persistent and transitory shocks in the model. Second, the college premium averaged 0.379 between 1965 and 1969 and does not require any adjustment, which is another empirical target we choose. Finally, the target for the average wage growth over the life cycle is 65 percent, which is broadly consistent with estimates from the Panel Study of Income Dynamics (cf., Gourinchas and Parker (2002), Guvenen (2005a)). ${ }^{22}$ See Guvenen and Kuruscu (2006) for a more detailed discussion of these parameter choices.

Skill-Biased Technical Change.-We assume that the skill bias of technology, $\theta_{H} / \theta_{L}$, starts to grow at a constant rate from 1970 until 1995. This is in contrast to the one-time jump assumption made in the theoretical section, but is likely to be more realistic and is consistent with how SBTC has been modeled in the previous empirical literature (see Katz and Murphy (1992)). The ending year, 1995, is chosen to be roughly consistent with the observation that the rise in wage inequality seems to have slowed down by the mid-1990s. The growth rate of $\theta_{H} / \theta_{L}$ is calibrated to 2.3 percent per year so that the model matches the level of overall wage inequality in the U.S. data in 1995 (the

i.i.d. shock process, respectively, with variances that remain stationary during the period under study.

${ }^{22}$ One caveat that should be noted is that these studies rely on data after 1970 since PSID is available from 1968 onward. However, we are not aware of estimates of life-cycle wage profiles using data prior to the 1970s. 
level of this target is also adjusted for the fact that the model has no shocks). ${ }^{23}$ Table 2 summarizes the baseline parameter choices.

\subsection{Evolution of Wage Inequality}

\subsubsection{Overall Wage Inequality}

We begin by analyzing the implications of the model for the evolution of total wage inequality during this period. The U.S. data on male wages used to construct the empirical figures in the rest of the paper have been provided to us by David Autor and are the same as in Autor, Katz, and Kearney (2005a,b). Figure 3 plots the variance of log wages generated by the model together with its empirical counterpart. ${ }^{24}$ Remember that the model is calibrated to match the levels of wage inequality in 1965-69 and 1995, and not the evolution between these end points. Yet, the model seems to capture the broad pattern during this period, with a slow increase in the 1970s that accelerates over time. As a result, most of the increase in overall wage inequality in the model happens starting in the 1980s, consistent with the U.S. data.

This pattern deserves some attention, as it is intimately related to the behavior of the college premium that we discuss later below. To understand the evolution of overall inequality, two separate effects, which sometimes work in opposite directions, should be noted. First, if there was no change in investment rates in response to SBTC (and therefore, the distribution of human capital remained unchanged over this period), this price effect would raise wage inequality at the same constant rate as the relative price change $\left(\theta_{H} / \theta_{L}\right)$. However, the investment rate does respond to SBTC, which is a key feature of this model. This effect works to offset the price effect early on, because individuals whose investment responds more to SBTC are exactly those with a higher ability and thus who have relatively more human capital already. As a result, the rise in wage inequality is depressed early on. Over time, however, the differential investment response leads to an even larger dispersion in human capital levels, which reinforces the price effect, and leads to an accelerating rise in wage inequality.

One notable divergence occurs during the 1980s when inequality rises faster in the data compared to the model. Some authors have emphasized the role played by the erosion of the legal minimum wage due to high inflation in the late 1970s, which resulted in the fall of wages in the lower tail of

\footnotetext{
${ }^{23}$ Despite the fact that $\theta_{L}$ is falling during SBTC (since $\theta_{H} / \theta_{L}$ is rising and $\theta_{L}+\theta_{H}=1$ ), the absolute productivity of raw labor, which is given by $Z \theta_{L}$, continues to grow (by 0.23 percent per year) during this period due to the sustained growth in $Z$. Therefore, with this calibration SBTC results only in a relative fall in the productivity of raw labor with respect to human capital.

${ }^{24}$ One difference between the construction of the empirical graph and the model counterpart should be noted. Autor, Katz, and Kearney (2005a) adjust for compositional changes over time, including those resulting from potential changes in the ability pool of college and high-school graduates over time. We do not make this adjustment in the quantitative model in this paper. It is also important to note that earlier studies that do not adjust for composition (cf., Card and Lemieux (2001) and Acemoglu (2002) among others) find a very similar shape for the college premium, so the difference is not likely to be crucial for our purposes.
} 
Figure 3: The Evolution of Wage and Consumption Inequality: 1965-2000

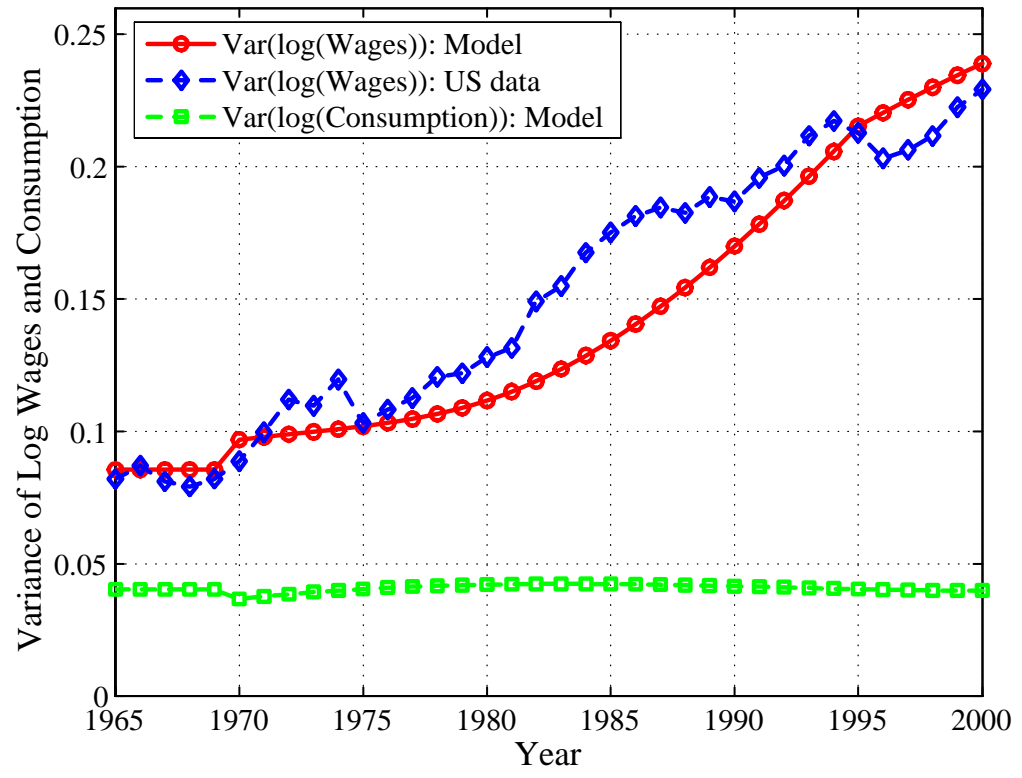

the distribution, thereby increasing inequality (cf., Card and Dinardo (2002)). This factor is not present in the model, which might explain the divergence from the data during the 1980s.

\subsubsection{Between-Group Wage Inequality (College Premium)}

Figure 4 illustrates the behavior of the college premium implied by the model along with its empirical counterpart. Recall that the only data point in this graph targeted in the calibration was the average level of the premium between 1965 and 1969. In the model, the college premium falls throughout the 1970s followed by a robust increase in the next two decades, showing an overall pattern that is remarkably consistent with the data.

In addition, several authors have documented that the decline in the college premium during the 1970s was mainly driven by the decline in the college premium among younger individuals (see Card and Lemieux (2001) and Autor, Katz, and Kearney (2005a)). In figure 5 we plot the college premium for two different experience groups (1-15 and 30-45) implied by the model. The college premium is higher among more experienced individuals before SBTC, which is consistent with the data. After SBTC, the initial decline and the strong rise in college premium are apparent among younger workers, but there is no fall among more experienced workers and the rise is slightly smaller as well. As a result, the gap between the older and younger workers widens initially (from 0.35 to 0.49 ) and then narrows (to 0.28). This result is driven by two channels. First, as discussed in the theoretical section, young individuals benefit less from the price effect in the short run, because 
Figure 4: The Evolution of the College Premium: Model versus Data, 1965-2000

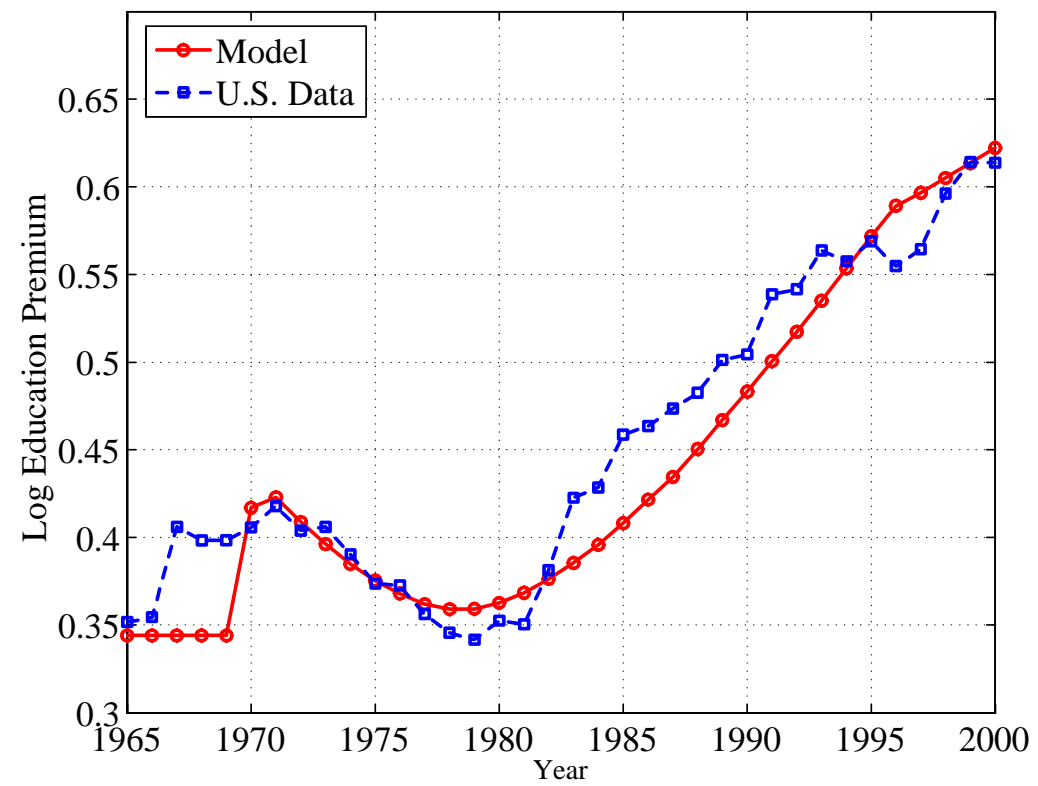

they have a smaller human capital stock, compared to old individuals. However, in the quantitative model there is a second channel that arises from relaxing the perpetual youth assumption: now young individuals face a longer planning horizon than the old, and hence have a larger marginal benefit from investing. Therefore, in response to SBTC, young individuals increase their investment more - and thus incur larger costs of investment - than the old, which further drives down the college premium among the young compared to that among the old.

The increase in the college premium among older workers in the model is more pronounced than in the U.S. data. One factor that could explain this discrepancy is the fact that our model assumes that all SBTC has been "disembodied." As a result, older workers who accumulated human capital before 1970 stand to gain as much as newer cohorts per unit of human capital. ${ }^{25}$

\subsection{Evolution of Average Wages}

Figure 6 plots the growth rates of median wages and labor productivity implied by the model. ${ }^{26}$ First, both series fall sharply immediately after the onset of SBTC in 1970. Hence, the model is

\footnotetext{
${ }^{25}$ See Greenwood and Yorukoglu (1997), Caselli (1999), and Violante (2002) for examples of models where improvements in technology come in the form of new vintages of machines that are more productive. In this case SBTC is embodied.

${ }^{26}$ Notice that since there is no capital in the model, total output equals total wages, implying that labor productivity (output per hour) equals the mean wage rate in the economy.
} 
Figure 5: The College Premium by Experience Level in the Model: 1965-2000

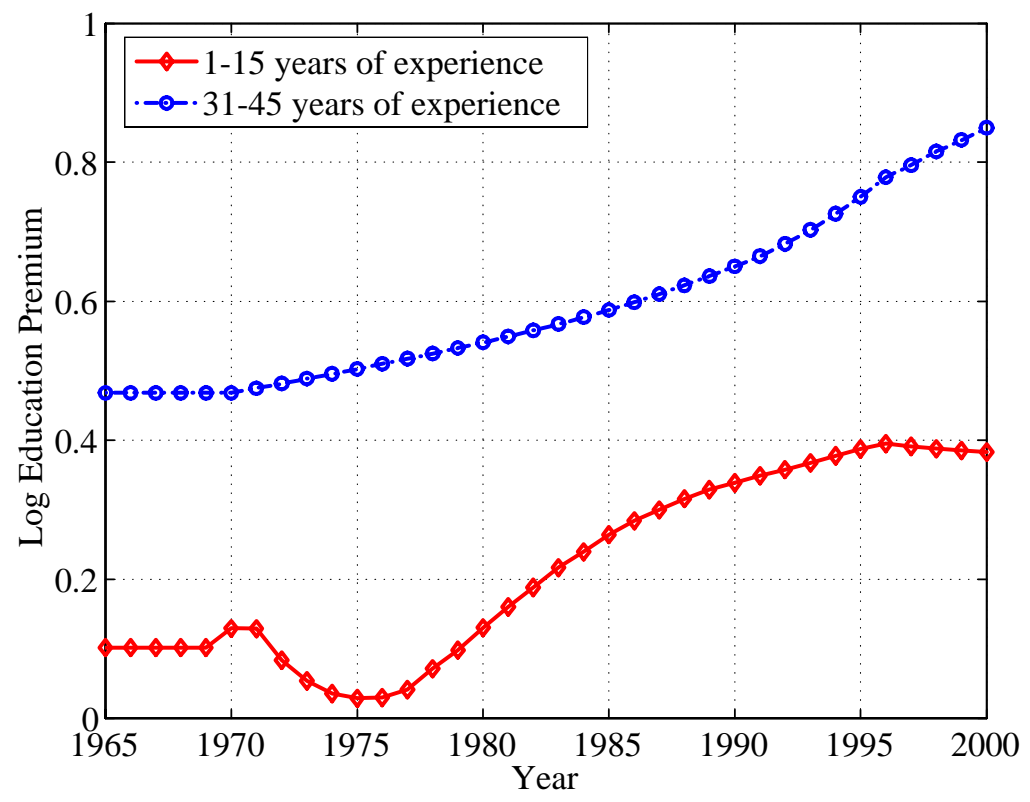

able to generate the sharp initial slowdown, but this happens three years earlier than in the data. This may suggest that our timing of the start of SBTC could be off by three years, or alternatively, that it took some time for individuals to fully realize its advent.

After the initial fall, the median wage continues to stagnate: it grows at 0.43 percent per year from 1970 to 1980, and averages 0.79 percent overall until 1995, representing a significant slowdown compared to the 1.5 percent growth during the period before 1970. Similarly, labor productivity grows by only 0.68 percent per year during the 1970s, but recovers faster and averages 1.27 percent per year until 1995. Overall, while the magnitude of slowdown is smaller than in the data, the model correctly predicts the qualitative aspects of this evolution, including the sharp initial fall, the sluggish nature of the subsequent recovery, and the fact that the slowdown was larger for median wages than it was for labor productivity.

The basic intuition for the slowdown in wage growth has been discussed earlier in the context of proposition 1. However, in the more general quantitative model here, there is an additional channel that plays an important role. To see this, recall that the increase in investment after SBTC can take one of two forms. First, it will both increase the fraction of individuals who invest full time (i.e., enroll in college) and lengthen the duration for those already planning to go to college. Since this change takes place at the upper tail of the ability distribution, the average ability of individuals who remain in the labor market continually falls during SBTC. Because individuals with lower ability also have low human capital on average, this "selection effect" reduces average wages and 
Figure 6: The Growth Rate of Median Wages and Labor Productivity in the Model: 1965-2000

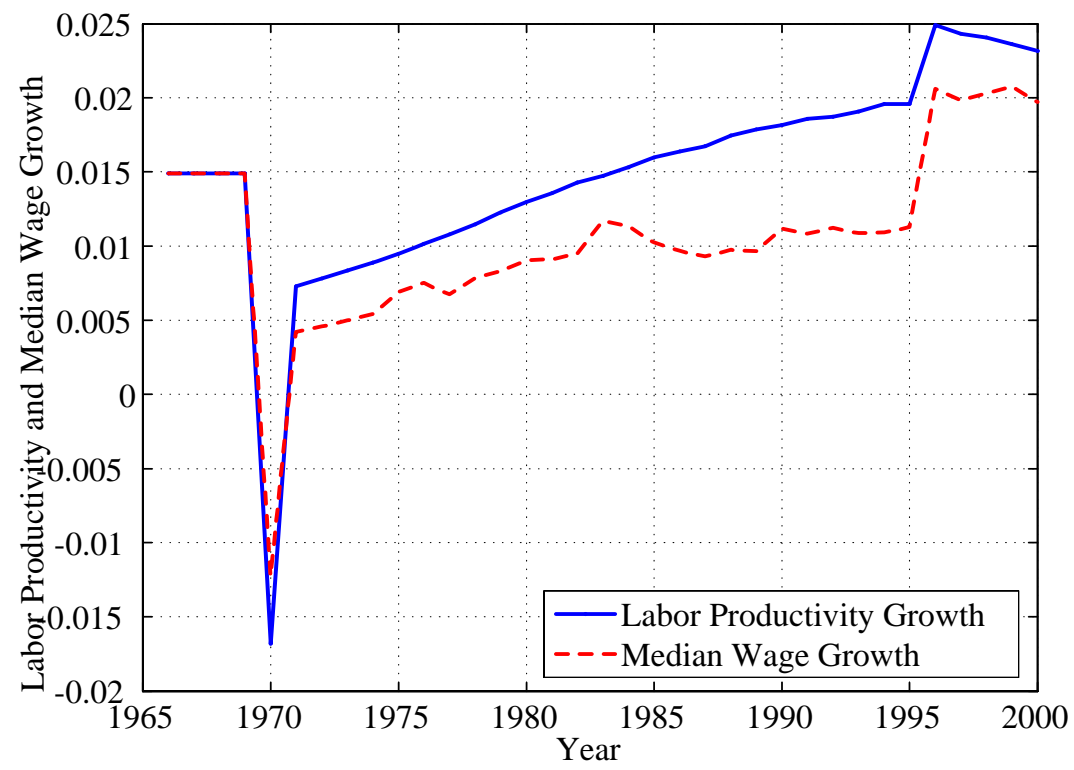

productivity after SBTC.

Second, those who remain in the labor market also respond to SBTC by increasing their onthe-job investment. The fraction of time invested before SBTC is 7.2 percent (or 2.9 hours in a 40-hour work week) and increases to reach 13.1 percent in 1995 (or 5.2 hours a week). Neither the initial investment level nor the increase during SBTC appears implausibly large to us, especially considering that what matters for average wages is the change in $(1-i)$, which goes from 93 percent down to 87 percent over 26 years. This "on-the-job investment effect" works in the same direction as the "selection effect" to further reduce wage growth after SBTC.

To sum up, during this period the labor market is dominated by individuals who have lower ability than before, but who also invest more than before, resulting in slow wage and productivity growth. Over time, the increase in the total human capital stock due to both types of investment begins to dominate, resulting in a recovery in both the median wage and labor productivity.

\subsection{Rise in Consumption Inequality — or Lack Thereof}

The present model abstracts from many features that would be important for a detailed analysis of consumption inequality (such as incomplete markets, retirement savings, demographic changes, etc.). But the model still addresses a simple but fundamental question: Has the substantial rise in cross-sectional wage inequality during this period resulted in a parallel rise in lifetime income inequality? Figure 3 plots the evolution of lifetime income (which equals consumption in the model) 
inequality, which shows a very small increase of 0.4 log points during SBTC.

At first blush, it seems surprising that wage inequality could rise in such a systematic fashion without a significant change in lifetime incomes. The mechanism has been discussed before in the context of figure 1. Essentially, the rise in future discounted benefits is not much larger than the increase in foregone earnings early in life, which keeps down the lifetime gain from human capital investment in response to SBTC. This result could partly be anticipated from the analysis in Kuruscu (2005), who showed that for a range of plausible parameter values, the total gain due to human capital investment is surprisingly small - no more than a few percent of lifetime income. Although in the present calibration we use some more conservative parameter values (in particular, we set $\alpha=0.80$ compared to 0.94 in that paper), which implies larger total gains from human capital investment compared to Kuruscu (2006), the exercise here is about the incremental gain from increasing one's investment level in response to SBTC. Therefore, this model offers a mechanism that is consistent with a large increase in wage inequality but a small change in lifetime inequality.

\section{Discussion and Conclusion}

In this paper we have examined the implications of a tractable general equilibrium model of human capital accumulation for several trends about the evolution of the wage distribution since the early 1970s. The key element in the model is the interaction between skill-biased technical change - which is interpreted broadly as a rise in the price of human capital - and heterogeneity in the ability to accumulate human capital. Because of the latter heterogeneity, the response of different individuals to SBTC is systematically different from each other. As a result, the model generates rich behavior in the relative wages of individuals depending on their age and ability. Since ability is not directly observable in the data but is crudely approximated by education, the rise in wage inequality among individuals with different ability levels appears as an increase in residual inequality.

The present model abstracts from several important features to isolate the contribution of the mechanism discussed above. One such assumption we made is that upon the arrival of SBTC, individuals fully know that the rise in the productivity (or in its growth rate, in Section 4) of human capital is permanent. In a companion paper (Guvenen and Kuruscu (2006)), we instead allow for individuals to learn about SBTC in a Bayesian fashion, and solve the model quantitatively. Under some plausible scenarios, this extension does not overturn the conclusions of the present paper, but new and interesting channels emerge from the interaction of learning and human capital accumulation. For example, the uncertainty brought about by Bayesian learning does not dampen investment incentives. This result can be anticipated from the optimality condition for investment choice (5): because $Q_{j, s}$ is a convex function of the sum of future skill prices, uncertainty about the future increases the investment in the economy. As a result, this extension in fact strengthens some of the results obtained here (such as the decline in the college premium in the short run). In some 
cases, even if individuals initially underestimate the rise in the average growth rate of skill prices due to SBTC, the uncertainty channel is sufficiently strong to counteract this underestimation.

Although we have focused exclusively on the evolution of the wage distribution in this paper, a related set of trends have been observed in educational attainment during this period. While the model also makes predictions about educational attainment and on-the-job training over time - in particular, that they will both increase in response to SBTC, which is broadly consistent with the data - it seems too stylized for a detailed study of the rich trends observed in the data. For studying these trends, one feature that seems important to account for is the fact that formal education uses inputs other than time (school buildings, educators, and so on) and these inputs are likely to have relatively inelastic supply in the short and perhaps intermediate run. For example, tuition costs (as well as the earnings of educators) have increased significantly since the early 1980s, which may partly reflect demand pressures resulting from SBTC on these inputs with relatively inelastic supply. Furthermore, formal education arguably teaches more general skills, whereas on-the-job training provides more specific skills. Incorporating these features would be an important extension of the present framework.

Finally, another area for future research is to study whether the mechanism proposed in this paper can also help understand the different experiences of several developed economies during this period (cf., Katz and Autor (1999)). To study this question, the current model can be extended to allow for differences in labor market institutions - and especially differences in the progressivity of income taxes and unionization rates - across countries and over time. Notice that progressivity and unionization share the key feature that they both make the wage structure more compressed, which in turn will hamper the incentives to accumulate human capital. For example, an economy which responds to SBTC by compressing the wage structure will not experience a large increase in inequality, but will also not be able to accumulate the requisite human capital, and therefore experience the growth surge that happens several decades after the onset of SBTC. In future work, we intend to explore the predictions of such a model systematically, and apply them to understand cross-country differences in inequality trends. 


\section{A Appendix: Derivations and Proofs of Propositions}

\section{Proof of Proposition 1}

Substituting the optimal investment level leads to the following expressions for the average wage before the shock and in the short run.

$$
\begin{gathered}
\bar{w}_{S R}=\theta_{L} l+\left(\frac{\delta}{1-\delta} \theta_{H}^{\prime}\left(\frac{\alpha \delta \beta}{1-\beta \delta} \theta_{H}\right)^{\alpha /(1-\alpha)}-\frac{\alpha \delta \beta}{1-\delta \beta} \theta_{H}^{\prime}\left(\frac{\alpha \delta \beta}{1-\beta \delta} \theta_{H}^{\prime}\right)^{\alpha /(1-\alpha)}\right) E[A] . \\
\bar{w}_{I}=\theta_{L} l+\left(\frac{\delta}{1-\delta} \theta_{H}\left(\frac{\alpha \delta \beta}{1-\beta \delta} \theta_{H}\right)^{\alpha /(1-\alpha)}-\frac{\alpha \delta \beta}{1-\delta \beta} \theta_{H}\left(\frac{\alpha \delta \beta}{1-\beta \delta} \theta_{H}\right)^{\alpha /(1-\alpha)}\right) E[A] .
\end{gathered}
$$

Then $w_{S R}<w_{I}$ iff

$$
\frac{\theta_{H}^{\prime}}{\theta_{H}}\left(\frac{\delta}{1-\delta}-\frac{\alpha \delta \beta}{1-\delta \beta}\left(\frac{\theta_{H}^{\prime}}{\theta_{H}}\right)^{\alpha /(1-\alpha)}\right)<\frac{\delta}{1-\delta}-\frac{\alpha \delta \beta}{1-\delta \beta} .
$$

To see under what conditions this inequality is satisfied, consider the function

$$
f(x)=x\left(\frac{\delta}{1-\delta}-\frac{\alpha \delta \beta}{1-\delta \beta} x^{\alpha /(1-\alpha)}\right) .
$$

Notice that a skill-biased technical change is equivalent to increasing $x=\frac{\theta_{H}^{\prime}}{\theta_{H}}$ above 1 . Therefore, if $f^{\prime}(1)<0$, $f^{\prime}(x)<0$ for $x>1$, then the inequality above is satisfied and $w_{S R}<w_{I}$.

$$
f^{\prime}(1)=\frac{\delta}{1-\delta}-\frac{\alpha \delta \beta}{(1-\delta \beta)(1-\alpha)}
$$

therefore $f^{\prime}(1)<0$ and $f^{\prime}(x)<0$ for $x>1$, iff $\frac{\delta}{1-\delta}-\frac{\alpha \delta \beta}{(1-\delta \beta)(1-\alpha)}<0$

\section{Corollary 2: Calculating the Transition time for Average Wages}

1. How long does it take for the average wage to complete half of the transition $\left(\left(\bar{w}_{L R}-\bar{w}_{S R}\right) / 2\right)$ ?

Average wage $t$ periods after the shock is given by

$$
\bar{w}_{t}=\theta_{L} l-C\left(\overline{\mathbf{Q}}^{\prime}\right)+\boldsymbol{\theta}_{H}^{\prime} \frac{\delta}{1-\delta} \overline{\mathbf{Q}}^{\prime}+\left(\bar{Q}-\overline{\mathbf{Q}}^{\prime}\right) \boldsymbol{\theta}_{H}^{\prime} \frac{\delta^{t+1}}{1-\delta} .
$$

Define the half-life of the transition to be the smallest integer, $t_{1}$, that satisfies

$$
\bar{w}_{t_{1}}-\bar{w}_{S R}>\left(\bar{w}_{L R}-\bar{w}_{S R}\right) / 2=\frac{1}{2} \frac{\delta}{1-\delta} \boldsymbol{\theta}_{H}^{\prime}\left(\overline{\mathbf{Q}}^{\prime}-\bar{Q}\right),
$$

where we substituted the definitions of $\bar{w}_{L R}$ and $\bar{w}_{S R}$ from equations (15) and (16) to obtain the second equality. The left-hand side of this last expression is

$$
\bar{w}_{t_{1}}-\bar{w}_{S R}=\bar{w}_{t_{1}}-\bar{w}_{0}=\frac{\delta}{1-\delta} \boldsymbol{\theta}_{H}^{\prime}\left(\overline{\mathbf{Q}}^{\prime}-\bar{Q}\right)\left(1-\delta^{t_{1}}\right)
$$

by using the definition of $\bar{w}_{t_{1}}$ above, and equation ((15)). Now, combining equations (26) and (27):

$$
\delta^{t_{1}}<\frac{1}{2} \Leftrightarrow t_{1}>-\frac{\log 2}{\log \delta},
$$


which can be solved for the minimum integer $t_{1}$. It is easy to see that the transition time $t_{1}$ is decreasing in $\delta$. So, the speed of convergence is higher when $\delta$ is smaller.

2. How long does it take for the average wage to reach its initial steady state level?

Normalize the period of shock to zero: $t^{*}=0$. Then for all $t>0$ we have

$$
\bar{w}_{t}-\bar{w}_{I}=-\boldsymbol{\theta}_{H}^{\prime} \overline{\mathbf{Q}}^{\prime}\{\underbrace{\left[\left(\frac{\theta_{H}}{\boldsymbol{\theta}_{H}^{\prime}}\right)^{1 /(1-\alpha)}-1\right]\left[\frac{\delta}{1-\delta}-\frac{\alpha \beta \delta}{1-\delta \beta}\right]}_{<0}+\underbrace{\left[1-\left(\frac{\theta_{H}}{\boldsymbol{\theta}_{H}^{\prime}}\right)^{\alpha /(1-\alpha)}\right]}_{>0} \frac{\delta^{t+1}}{1-\delta}\} .
$$

Under condition 1 , the average wage falls immediately after the shock: $\bar{w}_{1}-\bar{w}_{I}<0$. Then the expression above is going to increase monotonically and cross zero after some point. There exists a $t_{2}$ such that $\bar{w}_{I}-\bar{w}_{t}>0$ for $t \geq t_{2}$, which is the nearest integer larger than the $t^{+}$that solves

$$
\delta^{t^{+}}=\frac{1-\left(\frac{\theta_{H}}{\boldsymbol{\theta}_{H}^{\prime}}\right)^{1 /(1-\alpha)}}{1-\left(\frac{\theta_{H}}{\boldsymbol{\theta}_{H}^{\prime}}\right)^{\alpha /(1-\alpha)}}\left[\frac{1}{1-\delta}-\frac{\alpha \beta}{1-\delta \beta}\right](1-\delta)
$$

\section{Proof of Proposition 2}

Let

$$
\phi=\frac{\overline{Q_{c}}}{{\overline{Q_{n}}}_{n}}=\frac{{\overline{\mathbf{Q}_{c}}}^{\prime}}{{\overline{\mathbf{Q}_{n}}}^{\prime}}=\frac{E_{c}(A)}{E_{n}(A)} .
$$

Substitute $\overline{Q_{c}}=\phi \bar{Q}_{n}$ and $C\left(\bar{Q}_{n}\right)=\frac{\alpha \delta \beta}{1-\delta \beta} \theta_{H} \bar{Q}_{n}$ in the college premium to get

$$
\omega_{I}^{*}=\frac{\theta_{L} l+\phi \theta_{H} \bar{Q}_{n}\left(\frac{\delta}{1-\delta}-\frac{\alpha \delta \beta}{1-\delta \beta}\right)}{\theta_{L} l+\theta_{H} \bar{Q}_{n}\left(\frac{\delta}{1-\delta}-\frac{\alpha \delta \beta}{1-\delta \beta}\right)}
$$

and

$$
\omega_{L R}^{*}=\frac{\theta_{L} l+\phi \boldsymbol{\theta}_{H}^{\prime} \overline{\mathbf{Q}}_{n}^{\prime}\left(\frac{\delta}{1-\delta}-\frac{\alpha \delta \beta}{1-\delta \beta}\right)}{\theta_{L} l+\boldsymbol{\theta}_{H}^{\prime} \overline{\mathbf{Q}}_{n}^{\prime}\left(\frac{\delta}{1-\delta}-\frac{\alpha \delta \beta}{1-\delta \beta}\right)} .
$$

Since $\boldsymbol{\theta}_{H}^{\prime} \overline{\mathbf{Q}}_{n}^{\prime}>\theta_{H} \bar{Q}_{n}$, if the function $g(x)=\frac{\theta_{L} l+\phi x}{\theta_{L} l+x}$ is increasing in $x$, then $\omega_{L R}^{*}>\omega_{I}^{*}$.

$$
g^{\prime}(x)=\frac{\phi \theta_{L} l-\theta_{L} l}{\left(\theta_{L} l+x\right)^{2}}
$$

$g^{\prime}(x)$ is positive iff $\phi>1$. Then $\omega_{L R}^{*}>\omega_{I}^{*}$ iff $E_{c}(A)>E_{n}(A)$.

The premium in the short run can be written as

$$
\omega_{S R}^{*}=\frac{\theta_{L} l+\phi\left(\frac{\delta}{1-\delta} \boldsymbol{\theta}_{H}^{\prime} \bar{Q}_{n}-\frac{\alpha \delta \beta}{1-\beta \delta} \boldsymbol{\theta}_{H}^{\prime} \overline{\mathbf{Q}}_{n}^{\prime}\right)}{\theta_{L} l+\frac{\delta}{1-\delta} \boldsymbol{\theta}_{H}^{\prime} \bar{Q}_{n}-\frac{\alpha \delta \beta}{1-\beta \delta} \boldsymbol{\theta}_{H}^{\prime} \overline{\mathbf{Q}}_{n}^{\prime}}=\frac{\theta_{L} l+\phi x_{S R}}{\theta_{L} l+x_{S R}},
$$

where

$$
x_{S R}=\frac{\delta}{1-\delta} \boldsymbol{\theta}_{H}^{\prime} \bar{Q}_{n}-\frac{\alpha \delta \beta}{1-\beta \delta} \boldsymbol{\theta}_{H}^{\prime} \overline{\mathbf{Q}}_{n}^{\prime}
$$


Let

$$
x_{I}=\frac{\delta}{1-\delta} \theta_{H} \bar{Q}_{n}-\frac{\alpha \delta \beta}{1-\beta \delta} \theta_{H} \bar{Q}_{n}
$$

If $x_{S R}<x_{I}$, then $\omega_{S R}^{*}<\omega_{I}^{*}$. Therefore we will characterize the condition under which $x_{S R}<x_{I}$. Plugging optimal investment choices, we can show that $x_{S R}<x_{I}$ iff

$$
\frac{\boldsymbol{\theta}_{H}^{\prime}}{\theta_{H}}\left(\frac{\delta}{1-\delta}-\frac{\alpha \delta \beta}{1-\delta \beta}\left(\frac{\boldsymbol{\theta}_{H}^{\prime}}{\theta_{H}}\right)^{\alpha /(1-\alpha)}\right)<\frac{\delta}{1-\delta}-\frac{\alpha \delta \beta}{1-\delta \beta} .
$$

This is the same condition as in proposition 1, therefore $\omega_{S R}^{*}<\omega_{I}^{*}$ for all $\boldsymbol{\theta}_{H}^{\prime}>\theta_{H}$ if $\frac{\delta}{1-\delta}-\frac{\alpha \delta \beta}{(1-\delta \beta)(1-\alpha)}<0$

\section{Proof of Proposition 3}

The proof is very similar to the proof of proposition $\mathbf{2}$. Let

$$
\phi=\frac{\overline{Q_{c}}}{\overline{Q_{n}}}=\frac{{\overline{\mathbf{Q}_{c}}}^{\prime}}{\overline{\mathbf{Q}}_{n}^{\prime}}=\frac{E_{c}(A)}{E_{n}(A)} .
$$

The premium in the short run can be written as

$$
\omega_{S R}^{*}(s)=\frac{\theta_{L} l+\phi\left(\boldsymbol{\theta}_{H}^{\prime} \bar{Q}_{n}(s-1)-\frac{\alpha \delta \beta}{1-\beta \delta} \boldsymbol{\theta}_{H}^{\prime} \overline{\mathbf{Q}}_{n}^{\prime}\right)}{\theta_{L} l+\boldsymbol{\theta}_{H}^{\prime} \bar{Q}_{n}(s-1)-\frac{\alpha \delta \beta}{1-\beta \delta} \boldsymbol{\theta}_{H}^{\prime} \overline{\mathbf{Q}}_{n}^{\prime}}=\frac{\theta_{L} l+\phi x_{S R}}{\theta_{L} l+x_{S R}},
$$

where $x_{S R}=\boldsymbol{\theta}_{H}^{\prime} \bar{Q}_{n}(s-1)-\frac{\alpha \delta \beta}{1-\beta \delta} \boldsymbol{\theta}_{H}^{\prime} \overline{\mathbf{Q}}_{n}^{\prime}$. Let $x_{I}=\theta_{H} \bar{Q}_{n}(s-1)-\frac{\alpha \delta \beta}{1-\beta \delta} \theta_{H} \bar{Q}_{n}$.

The education premium declines in the short run iff $x_{S R}<x_{I}$.

$$
x_{S R}<x_{I} \Longleftrightarrow \frac{\boldsymbol{\theta}_{H}^{\prime}}{\theta_{H}}\left(s-1-\frac{\alpha \delta \beta}{1-\delta \beta}\left(\frac{\boldsymbol{\theta}_{H}^{\prime}}{\theta_{H}}\right)^{\alpha /(1-\alpha)}\right)<s-1-\frac{\alpha \delta \beta}{1-\delta \beta} .
$$

Define the function

$$
f_{s}(x)=x\left(s-1-\frac{\alpha \delta \beta}{1-\delta \beta} x^{\alpha /(1-\alpha)}\right) .
$$

Notice that a skill-biased technical change is equivalent to increasing $x=\frac{\theta_{H}^{\prime}}{\theta_{H}}$ above 1 . Therefore, if $f_{s}^{\prime}(1)<0$ then $\omega_{S R}^{*}(s)<\omega_{I}^{*}(s)$.

$$
f_{s}^{\prime}(1)<0 \Longleftrightarrow s<1+\frac{\alpha \delta \beta}{(1-\delta \beta)(1-\alpha)}
$$

Therefore, $\omega_{S R}^{*}(s)<\omega_{I}^{*}(s)$ if $s<1+\frac{\alpha \delta \beta}{(1-\delta \beta)(1-\alpha)}$.

The college premium in the long run is given by

$$
\omega_{L R}^{*}(s)=\frac{\theta_{L} l+\phi\left(s-1-\frac{\alpha \delta \beta}{1-\beta \delta}\right) \boldsymbol{\theta}_{H}^{\prime} \overline{\mathbf{Q}}_{n}^{\prime}}{\theta_{L} l+\left(s-1-\frac{\alpha \delta \beta}{1-\beta \delta}\right) \boldsymbol{\theta}_{H}^{\prime} \overline{\mathbf{Q}}_{n}^{\prime}} .
$$

Since $\boldsymbol{\theta}_{H}^{\prime} \overline{\mathbf{Q}}_{n}^{\prime}>\theta_{H} \bar{Q}_{n}$ and $\phi>1$, the college premium would increase in the long run if $s-1-\frac{\alpha \delta \beta}{1-\beta \delta}>0$. 


\section{Derivation of the Variances of Wages and Consumption}

The wage of an $s$-year-old individual of type $j$ who is $w_{j, s}=\theta_{L} l+\theta_{H} Q_{j}(s-1)-C_{j}\left(Q_{j}\right)$. We rewrite it as $w_{j, s}=m_{j}+p_{j}(s-1)$, where $m_{j}=\theta_{L} l-C_{j}\left(Q_{j}\right)$ and $p_{j}=\theta_{H} Q_{j}$.

The average wage is given by

$$
\bar{w}=\sum_{s=1}^{\infty}(1-\delta) \delta^{s-1} \int_{j} w_{j, s}=\sum_{s=1}^{\infty}(1-\delta) \delta^{s-1} \int_{j}\left[m_{j}+p_{j}(s-1)\right] .
$$

With some algebra we get

$$
\bar{w}=\bar{m}+\frac{\delta}{1-\delta} \bar{p}=\theta_{L} l-C(\bar{Q})+\frac{\delta}{1-\delta} \theta_{H} \bar{Q}=\theta_{L} l+\left(\frac{\delta}{1-\delta}-\frac{\alpha \delta \beta}{1-\delta \beta}\right) \theta_{H} \bar{Q},
$$

where

$$
\bar{m}=\theta_{L} l-\int_{j} C_{j}\left(Q_{j}\right)=\theta_{L} l-C(\bar{Q})=\theta_{L} l-\frac{\alpha \delta \beta}{1-\delta \beta} \theta_{H} \bar{Q}
$$

and $\bar{p}=\theta_{H} \int_{j} Q_{j}=\theta_{H} \bar{Q}$. Using the expression for $Q_{j}$, we get

$$
\bar{Q}=\left(\frac{\alpha \delta \beta}{1-\beta \delta} \theta_{H}\right)^{\alpha /(1-\alpha)} E[A]
$$

The consumption of type $j$ individual is $c_{j}=m_{j}+\frac{\beta \delta}{1-\beta \delta} p_{j}$. Then the average consumption is

$$
\bar{c}=\bar{m}+\frac{\delta \beta}{1-\delta \beta} \bar{p}=\theta_{L} l+\left(\frac{\delta \beta}{1-\delta \beta}-\frac{\alpha \delta \beta}{1-\delta \beta}\right) \theta_{H} \bar{Q}
$$

Variance of wages is given by

$$
\begin{aligned}
\operatorname{Var}(w) & =\int_{j} \sum_{s=1}^{\infty}(1-\delta) \delta^{s-1}\left[m_{j}+p_{j}(s-1)-\bar{m}-\frac{\delta}{1-\delta} \bar{p}\right]^{2} \\
& =\operatorname{Var}(m)+\frac{2 \delta}{1-\delta} \operatorname{Cov}(m, p)+\frac{\delta(1+\delta)}{(1-\delta)^{2}} \operatorname{Var}(p)+\frac{\delta}{(1-\delta)^{2}} \bar{p}^{2}
\end{aligned}
$$

and variance of consumption is

$$
\begin{aligned}
\operatorname{Var}(c)= & \int_{j}\left[m_{j}+\frac{\beta \delta}{1-\beta \delta} p_{j}-\bar{m}-\frac{\beta \delta}{1-\beta \delta} \bar{p}\right]^{2} \\
= & \operatorname{Var}(m)+\frac{2 \delta \beta}{1-\delta \beta} \operatorname{Cov}(m, p)+\frac{(\delta \beta)^{2}}{(1-\delta \beta)^{2}} \operatorname{Var}(p) \\
& \operatorname{Var}(m)=\left(\frac{\alpha \delta \beta}{1-\delta \beta}\right)^{2} \theta_{H}^{2} \operatorname{Var}(Q) \\
& \operatorname{Var}(p)=\theta_{H}^{2} \operatorname{Var}(Q)
\end{aligned}
$$




$$
\begin{aligned}
\operatorname{Cov}(m, p) & =-\frac{\alpha \delta \beta}{1-\delta \beta} \theta_{H}^{2} \operatorname{Var}(Q) \\
\operatorname{Var}(Q) & =\left(\frac{\alpha \delta \beta \theta_{H}}{1-\delta \beta}\right)^{2 \alpha /(1-\alpha)} \operatorname{Var}(A)
\end{aligned}
$$

Plugging in the expressions above, we get

$$
\begin{aligned}
& \operatorname{Var}(w)=\left(\frac{\delta(1+\delta)}{(1-\delta)^{2}}-\frac{2(\alpha \delta \beta) \delta}{(1-\delta \beta)(1-\delta)}+\frac{(\alpha \delta \beta)^{2}}{(1-\delta \beta)^{2}}\right) \theta_{h}^{2} \operatorname{Var}(Q)+\frac{\delta}{(1-\delta)^{2}} \theta_{h}^{2} \bar{Q}^{2} \\
& =\left(\frac{\delta(1+\delta)}{(1-\delta)^{2}}-\frac{2(\alpha \delta \beta) \delta}{(1-\delta \beta)(1-\delta)}+\frac{(\alpha \delta \beta)^{2}}{(1-\delta \beta)^{2}}\right)\left(\frac{\alpha \delta \beta}{1-\delta \beta}\right)^{2 \alpha /(1-\alpha)} \theta_{h}^{2 /(1-\alpha)} \operatorname{Var}(A) \\
& \quad+\frac{\delta}{(1-\delta)^{2}}\left(\frac{\alpha \delta \beta}{1-\delta \beta}\right)^{2 \alpha /(1-\alpha)} \theta_{H}^{2 /(1-\alpha)} E[A]^{2}
\end{aligned}
$$

and

$$
\begin{aligned}
\operatorname{Var}(c) & =\left[\frac{(1-\alpha) \delta \beta}{1-\delta \beta}\right]^{2} \theta_{h}^{2} \operatorname{Var}(Q) \\
& =\left[\frac{(1-\alpha) \delta \beta}{1-\delta \beta}\right]^{2}\left(\frac{\alpha \delta \beta}{1-\delta \beta}\right)^{2 \alpha /(1-\alpha)} \theta_{h}^{2 /(1-\alpha)} \operatorname{Var}(A) .
\end{aligned}
$$

Therefore in the formulas in the text:

$$
\begin{aligned}
& n_{1} \equiv\left(\frac{\delta(1+\delta)}{(1-\delta)^{2}}-\frac{2(\alpha \delta \beta) \delta}{(1-\delta \beta)(1-\delta)}+\frac{(\alpha \delta \beta)^{2}}{(1-\delta \beta)^{2}}\right)\left(\frac{\alpha \delta \beta}{1-\delta \beta}\right)^{2 \alpha /(1-\alpha)}>0, \\
& n_{2} \equiv \frac{\delta}{(1-\delta)^{2}}\left(\frac{\alpha \delta \beta}{1-\delta \beta}\right)^{2 \alpha /(1-\alpha)}>0, \quad n_{3} \equiv\left[\frac{(1-\alpha) \delta \beta}{1-\delta \beta}\right]^{2}\left(\frac{\alpha \delta \beta}{1-\delta \beta}\right)^{2 \alpha /(1-\alpha)}>0 \\
& n_{4} \equiv\left(\frac{\delta}{1-\delta}-\frac{\alpha \delta \beta}{1-\delta \beta}\right)\left(\frac{\alpha \delta \beta}{1-\beta \delta}\right)^{\alpha /(1-\alpha)}>0 .
\end{aligned}
$$

\section{Proof of Proposition 4}

a. Long run:

$$
\begin{aligned}
& \left.C V(w)^{2}\right|_{\theta_{H}^{\prime}}-\left.C V(w)^{2}\right|_{\theta_{H}} \\
= & \frac{n_{1} \operatorname{Var}(A)+n_{2} E[A]^{2}}{\bar{w}^{\prime 2}} \theta_{h}^{\prime 2 /(1-\alpha)}-\frac{n_{1} \operatorname{Var}(A)+n_{2} E[A]^{2}}{\bar{w}^{2}} \theta_{h}^{2 /(1-\alpha)} \\
= & \left(n_{1} \operatorname{Var}(A)+n_{2} E[A]^{2}\right)\left(\frac{\theta_{h}^{\prime 2 /(1-\alpha)}}{\bar{w}^{\prime 2}}-\frac{\theta_{h}^{2 /(1-\alpha)}}{\bar{w}^{2}}\right)
\end{aligned}
$$

where $\bar{w}$ and $\bar{w}^{\prime}$ are the average wages in the old and new steady. Plugging in

$$
\bar{w}=\theta_{L} l+\left(\frac{\delta}{1-\delta}-\frac{\alpha \delta \beta}{1-\delta \beta}\right)\left(\frac{\alpha \delta \beta}{1-\beta \delta}\right)^{\alpha /(1-\alpha)} \theta_{H}^{1 /(1-\alpha)} E[A]
$$


and

$$
\bar{w}^{\prime}=\theta_{L} l+\left(\frac{\delta}{1-\delta}-\frac{\alpha \delta \beta}{1-\delta \beta}\right)\left(\frac{\alpha \delta \beta}{1-\beta \delta}\right)^{\alpha /(1-\alpha)} \theta_{H}^{\prime 1 /(1-\alpha)} E[A]
$$

we get

$$
\begin{aligned}
& \left.C V(w)^{2}\right|_{\theta_{H}^{\prime}}-\left.C V(w)^{2}\right|_{\theta_{H}} \\
= & \theta_{L} l\left\{n_{1} \operatorname{Var}(A)+n_{2} E[A]^{2}\right\}\left[\theta_{H}^{\prime 1 /(1-\alpha)} \bar{w}+\theta_{H}^{1 /(1-\alpha)} \bar{w}^{\prime}\right] \times \frac{\theta_{H}^{1 /(1-\alpha)}-\theta_{H}^{1 /(1-\alpha)}}{\bar{w}^{2} \bar{w}^{\prime 2}} .
\end{aligned}
$$

Since $n_{1}$ and $n_{2}$ are positive, and $\theta_{H}^{\prime}>\theta_{H}$,

$$
\left.C V(w)^{2}\right|_{\theta_{H}^{\prime}}-\left.C V(w)^{2}\right|_{\theta_{H}}>0
$$

An alternative way is to look at the derivative of $\left.C V(w)^{2}\right|_{\theta_{H}}$ with respect to $\theta_{H}$. It is easy to see that in fact $\left.C V(w)^{2}\right|_{\theta_{H}}$ increases with $\theta_{H}$.

b. Short run: Remember that the wage in the short run is

$$
w_{j, s}^{S R}=\underbrace{\theta_{L} l-C_{j}\left(\mathbf{Q}_{j}^{\prime}\right)}_{m_{j}^{\prime}}+\underbrace{\boldsymbol{\theta}_{H}^{\prime} Q_{j}}_{p_{j}^{\prime}}(s-1) .
$$

Notice that the difference between $w_{j, s}$ and $w_{j, s}^{S R}$ is that we have replaced $m_{j}$ and $p_{j}$ with $m_{j}^{\prime}$ and $p_{j}^{\prime}$. Hence the average wage in the short run is $\bar{w}_{S R}=\bar{m}^{\prime}+\frac{\delta}{1-\delta} \bar{p}^{\prime}$ and the variance of wages in the short run is

$$
\begin{aligned}
& \operatorname{Var}_{S R}(w)=\operatorname{Var}\left(m^{\prime}\right)+\frac{2 \delta}{1-\delta} \operatorname{Cov}\left(m^{\prime}, p^{\prime}\right)+\frac{\delta(1+\delta)}{(1-\delta)^{2}} \operatorname{Var}\left(p^{\prime}\right)+\frac{\delta}{(1-\delta)^{2}} \bar{p}^{2} \text {. } \\
& \operatorname{Var}\left(m^{\prime}\right)=\left(\frac{\alpha \delta \beta}{1-\delta \beta} \boldsymbol{\theta}_{H}^{\prime}\right)^{2} \times \underbrace{\operatorname{Var}\left(\mathbf{Q}^{\prime}\right)} \\
& =\left(\frac{\alpha \delta \beta}{1-\delta \beta} \boldsymbol{\theta}_{H}^{\prime}\right)^{2}\left(\frac{\boldsymbol{\theta}_{H}^{\prime}}{\theta_{H}}\right)^{2 \alpha /(1-\alpha)} \operatorname{Var}(Q) \\
& \operatorname{Var}\left(p^{\prime}\right)=\theta_{H}^{\prime 2} \operatorname{Var}(Q) \\
& \operatorname{Cov}\left(m^{\prime}, p^{\prime}\right)=-\frac{\alpha \delta \beta}{1-\delta \beta} \theta_{H}^{\prime 2} \operatorname{Cov}\left(Q, \mathbf{Q}^{\prime}\right) \\
& \operatorname{Cov}\left(Q, \mathbf{Q}^{\prime}\right)=\left(\frac{\boldsymbol{\theta}_{H}^{\prime}}{\theta_{H}}\right)^{\alpha /(1-\alpha)} \operatorname{Var}(Q)
\end{aligned}
$$

Then we can write the variance in the short run as

$\operatorname{Var}_{S R}(w)=\left\{\left(\frac{(\alpha \delta \beta)^{2}}{(1-\delta \beta)^{2}} x^{2 /(1-\alpha)}-\frac{2 \alpha \delta^{2} \beta}{(1-\delta \beta)(1-\delta)} x^{(2-\alpha) /(1-\alpha)}+\frac{\delta(1+\delta)}{(1-\delta)^{2}} x^{2}\right) \operatorname{Var}(Q)+\frac{\delta}{(1-\delta)^{2}} \bar{Q}^{2} x^{2}\right\} \theta_{h}^{2}$

where $x=\boldsymbol{\theta}_{H}^{\prime} / \theta_{H}$. Similarly the average wage in the short run can be written as

$$
\bar{w}_{S R}=\theta_{L} l+\left(\frac{\delta}{1-\delta} x-\frac{\alpha \delta \beta}{1-\delta \beta} x^{1 /(1-\alpha)}\right) \theta_{H} \bar{Q} .
$$


We look at what happens to $C V_{S R}^{2}(w)$ if $x$ is increased marginally above one, or equivalently $\boldsymbol{\theta}_{H}^{\prime}$ is increased marginally above $\theta_{H}$. Hence we compute

$$
\frac{d}{d x} C V_{S R}^{2}(w)=2 \frac{\frac{\bar{w}_{S R}}{2} \frac{d}{d x} \operatorname{Var}_{S R}(w)-\operatorname{Var}_{S R}(w) \frac{d}{d x} \bar{w}_{S R}}{\bar{w}_{S R}^{3}} .
$$

If $\frac{d}{d x} C V_{S R}^{2}(w)>0$ then we conclude that inequality increases in the short run with an increase in price of human capital. Since wage is positive, $\frac{d}{d x} C V_{S R}^{2}(w)$ would be positive if $\frac{\bar{w}_{S R}}{2} \frac{d}{d x} \operatorname{Var}_{S R}(w)-\operatorname{Var}_{S R}(w) \frac{d}{d x} \bar{w}_{S R}>$ 0 . Then we look at this expression at $x=1$, which is equal to

$$
\begin{aligned}
& \frac{\bar{w}_{S R}}{2} \frac{d}{d x} \operatorname{Var}_{S R}(w)-\operatorname{Var}_{S R}(w) \frac{d}{d x} \bar{w}_{S R} \\
& =\left\{\left[\frac{1}{1-\alpha} \frac{(\alpha \delta \beta)^{2}}{(1-\delta \beta)^{2}}-\frac{2-\alpha}{1-\alpha} \frac{2 \alpha \delta^{2} \beta}{(1-\delta \beta)(1-\delta)}+\frac{\delta(1+\delta)}{(1-\delta)^{2}}\right] \operatorname{Var}(Q)+\frac{\delta}{(1-\delta)^{2}} \bar{Q}^{2}\right\} \\
& \times\left\{\theta_{L} l+\left(\frac{\delta}{1-\delta}-\frac{\alpha \delta \beta}{1-\delta \beta}\right) \theta_{H} \bar{Q}\right\} \\
& -\theta_{H} \bar{Q}\left(\frac{\delta}{1-\delta}-\frac{\alpha \delta \beta}{(1-\delta \beta)(1-\alpha)}\right) \\
& \times\left\{\left(\frac{(\alpha \delta \beta)^{2}}{(1-\delta \beta)^{2}}-\frac{2 \alpha \delta^{2} \beta}{(1-\delta \beta)(1-\delta)}+\frac{\delta(1+\delta)}{(1-\delta)^{2}}\right) \operatorname{Var}(Q)+\frac{\delta}{(1-\delta)^{2}} \bar{Q}^{2}\right\} .
\end{aligned}
$$

Evaluating this expression at $\beta=1$ gives

$$
\frac{\delta}{(1-\delta)^{2}}\left\{(1+\delta-2 \alpha \delta) \operatorname{Var}(Q) \theta_{L} l+\theta_{L} l \bar{Q}^{2}+\frac{\alpha \delta^{2}}{1-\delta} \theta_{H} \bar{Q}^{3}+\left(1-\alpha^{2}+\alpha^{2} \delta\right) \frac{\alpha \delta^{2}}{(1-\delta)(1-\alpha)} \theta_{H} \bar{Q} \operatorname{Var}(Q)\right\} .
$$
$\beta=1$

Notice: $1+\delta-2 \alpha \delta>0$ and $1-\alpha^{2}+\alpha^{2} \delta>0$ for all $\alpha \leq 1$. Therefore, $\left.\frac{d}{d x} C V_{S R}^{2}(w)\right|_{x=1}>0$ when

\section{B Within-Group Wage Inequality}

A well-known empirical fact, first documented by Juhn, Murphy, and Pierce (1993), is that the wage growth in a given percentile of the wage distribution during SBTC has been monotonically related to the ranking of that percentile before SBTC. In particular, wages in the higher percentiles in 1963 also experienced high growth from 1963 to 1989, while the opposite happened at lower percentiles. This resulted in an increase in the wage inequality that was spread to all parts of the wage distribution. The following proposition states that the same outcome happens in the present model.

Proposition 6 (Within-Group Inequality) Let $w_{I}(\Omega)$ be the average wage at the $\Omega^{\text {th }}$ percentile of the wage distribution before $S B T C$ and $w_{L R}(\Omega)$ be the average wage at the $\Omega^{\text {th }}$ percentile of the wage distribution in the new steady state after SBTC. Then, $w_{L R}(\Omega) / w_{I}(\Omega)$ is increasing in $\Omega$.

Juhn, Murphy, and Pierce (1993, figure 5) also show that the same fanning out of the wage distribution is obtained when one conditions on a given age group. This is also true in the present model. The intuition is simple and can already be seen from figure 1, which shows that a higher price of human capital stretches out the wage distribution at every age (above a threshold) without a change in the relative ranking of individuals. Therefore, individuals who earn high wages before SBTC also experience a larger increase in their wages after SBTC (except for very young individuals). The next corollary states this result, and the proof follows. 
Corollary 4 Let $w_{I}(\Omega \mid s)$ and $w_{L R}(\Omega \mid s)$ be the average wage at the $\Omega^{\text {th }}$ percentile of the wage distribution conditional on age before SBTC and in the new steady state after SBTC, respectively. Then, $w_{L R}(\Omega \mid s) / w_{I}(\Omega \mid s)$ is increasing in $\Omega$ when $s>\underline{s}$.

\section{Proof of Proposition 6}

Remember that $w_{s, j}=\theta_{L} l+\theta_{H} Q_{j}(s-1)-C\left(Q_{j}\right)$. Plugging in the optimal investment, we can write $w_{s, j}=\theta_{L} l+n_{5} \theta_{H}^{1 /(1-\alpha)} y$, where $n_{5}=\left(\frac{\alpha \delta \beta}{1-\beta \delta}\right)^{\alpha /(1-\alpha)}$ and $y=\left(s-1-\frac{\alpha \delta \beta}{1-\beta \delta}\right) A$. It is clear that $w_{s, j}$ is increasing in $y$. Hence, one's relative position $\Omega$ in the wage distribution is positively related to $y$.

The wage of an agent with $y$ before the shock is given by $w_{I}(y)=\theta_{L} l+n_{5} \theta_{H}^{1 /(1-\alpha)} y$. The corresponding wage in the long run is $w_{L R}(y)=\theta_{L} l+n_{5} \boldsymbol{\theta}_{H}^{\prime 1 /(1-\alpha)} y$. It is then easy to show that $w_{L R}(y) / w_{I}(y)$ is increasing in $y$.

\section{References}

[1] Acemoglu, Daron (1998): "Why Do New Technologies Complement Skills? Directed Technical Change and Wage Inequality," Quarterly Journal of Economics, Vol. 113, pp. 1055-1089.

[2] Acemoglu, Daron (2002): "Technical Change, Inequality, and Labor Market," Journal of Economic Literature, March 2002, pp. 7-72.

[3] Aghion, Philippe, Peter Howitt, and Gianluca Violante (2002): "General Purpose Technology and Wage Inequality," Journal of Economic Growth, Vol. 7(4), pp. 315-345.

[4] Attanasio, Orazio, Erich Battistin, and Hidehiko Ichimura (2004): "What Really Happened to Consumption Inequality in the US?" IFS Working paper.

[5] Autor, David, Lawrence F. Katz, Alan B. Krueger (1998): "Computing Inequality: Have Computers Changed the Labor Market?" Quarterly Journal of Economics, Vol. 113, pp. 11691214 .

[6] Autor, David H., Lawrence F. Katz, and Melissa S. Kearney (2004): "Trends in U.S. Wage Inequality: Re-Assessing the Revisionists," Slides from earlier version of (2005a) paper.

[7] Autor, David H., Lawrence F. Katz, and Melissa S. Kearney (2005a): "Trends in U.S. Wage Inequality: Re-Assessing the Revisionists," MIT working paper.

[8] Autor, David H., Lawrence F. Katz, and Melissa S. Kearney (2005b): "Rising Wage Inequality: The Role of Composition and Prices," MIT working paper.

[9] Baker, Michael (1997): "Growth-Rate Heterogeneity and the Covariance Structure of LifeCycle Earnings," Journal of Labor Economics, Vol. 15, pp. 338-375.

[10] Becker, Gary S. (1965): Human Capital: A Theoretical and Empirical Analysis, with Special Reference to Education, reprinted 1994, Chicago: University of Chicago Press.

[11] Ben-Porath, Yoram (1967): "The Production of Human Capital and the Life Cycle of Earnings," Journal of Political Economy, Vol. 75(4), pp. 352-365. 
[12] Berman, Eli, John Bound, and Zvi Griliches (1994): "Changes in the Demand for Skilled Labor Within U.S. Manufacturing Industries: Evidence from the Annual Survey of Manufactures," Quarterly Journal of Economics, Vol. 109, pp. 367-365.

[13] Blanchard, Olivier (1985): "Deficits, Debt and Finite Horizons," Journal of Political Economy, Vol 93, pp. 223-247.

[14] Bound, John, and George Johnson (1992): "Changes in the Structure of Wages in the 1980's: An Evaluation of Alternative Explanations," American Economic Review, Vol. 82, pp. 371-392.

[15] Card, David, and John Dinardo (2002): "Skill Biased Technological Change and Rising Wage Inequality: Some Problems and Puzzles," Journal of Labor Economics, Vol. 20, pp. 733-783.

[16] Card, David, and Thomas Lemieux (2001): "Can Falling Supply Explain the Rising Return to College for Younger Men? A Cohort-Based Analysis," Quarterly Journal of Economics, Vol. 116, pp. 705-746.

[17] Caselli, Francesco (1999): "Technological Revolutions," American Economic Review, Vol. 89(1), pp. 78-102.

[18] Galor, Oded, and Omer Moav (2000): “Ability Biased Technological Transition, Wage Inequality and Economic Growth," Quarterly Journal of Economics, Vol. 115, pp. 469-497.

[19] Galor, Oded, and Daniel Tsiddon (1998): "Technological Progress, Mobility and Economic Growth," American Economic Review, Vol. 87, pp. 363-382.

[20] Gould, Eric, Omar Moav, and Bruce Weinberg (2001): "Precautionary Demand for Education, Inequality, and Technological Progress," Journal of Economic Growth, Vol. 6, pp. 285-315.

[21] Gourinchas Pierre-Olivier, and Jonathan A. Parker (2002): "Consumption Over the Life Cycle," Econometrica, Vol. 70, pp. 47-89.

[22] Greenwood, Jeremy, and Mehmet Yorukoglu (1997): “1974,” Carnegie Rochester Conference on Public Policy, Vol. 46, pp. 49-94.

[23] Guvenen, Fatih (2005a): "An Empirical Investigation of Labor Income Processes," Working paper, University of Texas at Austin.

[24] Guvenen, Fatih (2005b): "Learning Your Earning: Are Labor Income Shocks Really Very Persistent?" Working Paper, University of Texas at Austin.

[25] Guvenen, Fatih, and Burhanettin Kuruscu (2006): "A Quantitative Analysis of Rising Inequality: Ben-Porath Meets Skill-Biased Technical Change," Working Paper, University of Texas at Austin.

[26] Heckman, James J. (1976): "A Life-cycle Model of Earnings, Learning, and Consumption," Journal of Political Economy, Vol. 84(4), pp. 11-44.

[27] Heckman, James J., Lance J. Lochner, and Christopher R. Taber (1998): "Explaining Rising Wage Inequality: Explorations with a Dynamic General Equilibrium Model of Labor Earnings with Heterogenous Agents," Review of Economic Dynamics, Vol. 1(1), pp. 1-58. 
[28] Huggett, Mark, Gustavo Ventura, and Amir Yaron (2005): "Sources of Life-Cycle Inequality," Working Paper, Wharton School, University of Pennsylvania.

[29] Juhn, Chinhui, Kevin M. Murphy, and Brooks Pierce (1993): "Wage Inequality and the Rise in Returns to Skill," Journal of Political Economy, Vol. 101(3), pp. 410-442.

[30] Katz, Lawrence F., and David H. Autor (1999): "Changes in the Wage Structure and Earnings Inequality," in Orley Ashenfelter and David Card, eds., Handbook of Labor Economics, Vol. 3A, Amsterdam: Elsevier-North Holland, pp. 1463-1555.

[31] Katz, Lawrence F., and Kevin Murphy (1992): "Changes in Relative Wages, 1963-1987: Supply and Demand Factors," Quarterly Journal of Economics, Vol. 107(1), pp. 35-78.

[32] Krueger, Dirk, and Fabrizio Perri (2006): "Does Income Inequality Lead to Consumption Inequality? Evidence and Theory." Review of Economic Studies, Vol. 73(1), pp. 163-193.

[33] Krusell, Per, Lee Ohanian, José-Victor Ríos-Rull, and Giovanni L. Violante (2000), "CapitalSkill Complementarity and Inequality: A Macroeconomic Analysis," Econometrica, Vol. 68, pp. 1029-1054.

[34] Kuruscu, Burhanettin (2006): "Training and Lifetime Income," American Economic Review, Vol. 96(3), pp. 832-846.

[35] Lillard, Lee A., and Yoram A. Weiss (1979): "Components of Variation in Panel Earnings Data: American Scientists, 1960-70," Econometrica, Vol. 47, pp. 437-454.

[36] Machin, Stephen, and John Van Reenen (1998): "Technology and Changes in Skill Structure: Evidence from Seven OECD Countries," Quarterly Journal of Economics, Vol. 113(4), pp. $1215-1244$.

[37] Murphy, Kevin M., and Finis Welch (1992): "The Structure of Wages," Quarterly Journal of Economics, Vol. 107, pp. 285-326.

[38] Violante, Giovanni L. (2002): "Technological Acceleration, Skill Transferability, and the Rise in Residual Inequality," Quarterly Journal of Economics, Vol. 117, pp. 297-338. 